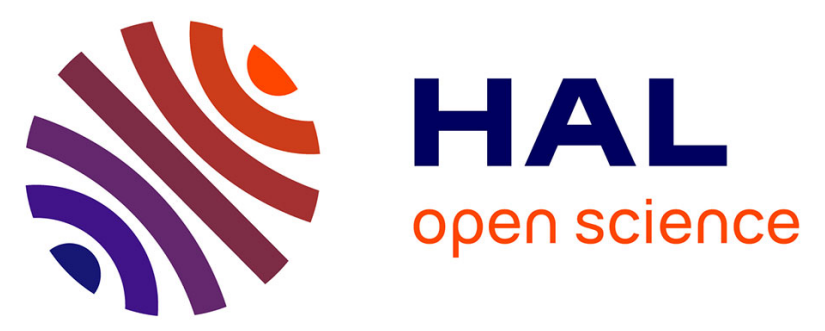

\title{
Highlights from a review of microplastics in marine sediments
}

\author{
Nam Ngoc Phuong, Vincent Fauvelle, Christian Grenz, Melanie Ourgaud, \\ Natascha Schmidt, Emilie Strady, Richard Sempere
}

\section{To cite this version:}

Nam Ngoc Phuong, Vincent Fauvelle, Christian Grenz, Melanie Ourgaud, Natascha Schmidt, et al.. Highlights from a review of microplastics in marine sediments. Science of the Total Environment, inPress, 777, pp.146225. 10.1016/j.scitotenv.2021.146225 . hal-03164736

\section{HAL Id: hal-03164736 https://hal-amu.archives-ouvertes.fr/hal-03164736}

Submitted on 12 Mar 2021

HAL is a multi-disciplinary open access archive for the deposit and dissemination of scientific research documents, whether they are published or not. The documents may come from teaching and research institutions in France or abroad, or from public or private research centers.
L'archive ouverte pluridisciplinaire HAL, est destinée au dépôt et à la diffusion de documents scientifiques de niveau recherche, publiés ou non, émanant des établissements d'enseignement et de recherche français ou étrangers, des laboratoires publics ou privés.

\section{(1) (1) $\$$}

Distributed under a Creative Commons Attribution - NonCommercial - NoDerivatives| 4.0 


\section{Journal Pre-proof}

Highlights from a review of microplastics in marine sediments

Nam Ngoc Phuong, Vincent Fauvelle, Christian Grenz, Mélanie

Ourgaud, Natascha Schmidt, Emilie Strady, Richard Sempéré

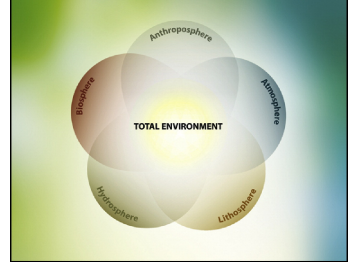

PII:

S0048-9697(21)01293-6

DOI:

https://doi.org/10.1016/j.scitotenv.2021.146225

Reference:

STOTEN 146225

To appear in:

Science of the Total Environment

Received date:

2 December 2020

Revised date:

7 February 2021

Accepted date:

25 February 2021

Please cite this article as: N.N. Phuong, V. Fauvelle, C. Grenz, et al., Highlights from a review of microplastics in marine sediments, Science of the Total Environment (2021), https://doi.org/10.1016/j.scitotenv.2021.146225

This is a PDF file of an article that has undergone enhancements after acceptance, such as the addition of a cover page and metadata, and formatting for readability, but it is not yet the definitive version of record. This version will undergo additional copyediting, typesetting and review before it is published in its final form, but we are providing this version to give early visibility of the article. Please note that, during the production process, errors may be discovered which could affect the content, and all legal disclaimers that apply to the journal pertain.

(C) 2021 Published by Elsevier. 


\section{Highlights from a review of microplastics in marine sediments}

Nam Ngoc Phuong ${ }^{1,2}$; Vincent Fauvelle ${ }^{1}$; Christian Grenz ${ }^{1}$; Mélanie Ourgaud ${ }^{1}$; Natascha Schmidt ${ }^{1}$; Emilie $\mathrm{Strady}^{1}$; Richard Sempéré ${ }^{1, *}$

${ }^{1}$ Aix-Marseille Univ., Toulon University, CNRS, IRD, M I O, UM 110, Marseille, France

${ }^{2}$ PhuTho college of Medicine and Pharmacy, 2201 Hung Vuo. o Boulevard, Viettri City, PhuTho Province, 290000, Viet Nam

*Author to whom correspondence should be ardre _ed; E-Mail: richard.sempere@mio.osupytheas.fr

Keywords: Microp ${ }^{1}$ as i ${ }^{i}, \mathrm{n}$ arine sediment, Raman, FTIR, nanoplastic.

Submitted to Science of the Total Environment

Revised version

February $7^{\text {th }}, 2021$ 


\begin{abstract}
The ubiquity of microplastics (MPs) has now been demonstrated throughout Earth's geographic areas in both terrestrial and marine environments. Marine ecosystems are the end point of the plastic waste cycle, and marine sediments are increasingly considered to be a sink for plastic debris, with possible deleterious effects on seafloor ecosystems. However, the low concentration of MPs in a complex matrix such as marine sediment makes their reliable analysis difficult. MP concentration in marine sediments is usually determined by various extraction procedures followed by optical, spectroscopy or mass spectrometry techniques, and are therefore hard to compare. Therefore, reliable determina: in of MPs in sediment is a challenging task. Here we present a short review on scua ss dealing with analytical determination protocols and MP detection in marine sedir en $?$ and discuss the advantages of the different techniques used. This analysis of the literaı re reveals that most of the 70 studies were carried out in European and Asian coastal ex riro iments. The use of $\mathrm{NaCl}$ saturated solution, hydrogen peroxide $\left(\mathrm{H}_{2} \mathrm{O}_{2}\right)$ and Fourier transform infrared spectroscopy (FTIR) are by far the most-used techniques for the $d_{1}$ ar nt steps of separation, digestion and identification, respectively. Based on thi ${ }^{-}$bo y oi literature, we present recommendations and suggestions for future research in order to 1 : crease the reliability of results and to facilitate inter-comparison. The use of $\mathrm{NaCl}$ rara the separation and digestion ste ${ }_{\mathrm{r}}^{-}$. spectively, whereas during the filtration step it is necessary to choose filter to se hased on the identification technique. More thorough investigation is needed to $\checkmark$ tablish a systematic protocol for MP identification. A combination of techniqu es vould permit to identify all items, and personal bias could be avoided if automatic idu. ${ }^{+} 111$ cation was implemented. Nanoplastics (NP) occurrence in marine sediments is also discussed, although no data are available to date.
\end{abstract}

\title{
Graphical abstract:
}

\begin{tabular}{|c|c|c|c|}
\hline Sampling & Ex & Analysis & Results \\
\hline & & $\begin{array}{ll}\cdot & \text { Microscopy } \\
\dot{\cdot} & \text { SEM } \\
\dot{\text { P }} & \text { Ram-GC-MS } \\
\text { - } & \text { FTIR }\end{array}$ & $\begin{array}{l}\text { - } \quad \mathrm{MP} / \mathrm{kg}, \mathrm{m}^{2}, \mathrm{~L} \\
\text { - } \mathrm{MP} \text { characteristics } \\
\text {. PE, PP, PVC } \\
\text {. Fiber, fragment } \\
\text { - } \mu \mathrm{m} \text { m black }\end{array}$ \\
\hline $\begin{array}{l}\text { Clean materials } \\
\geq 5 \text { replicates } \\
\text { Storage } \\
\text { Sediment } \\
\text { characteristics }\end{array}$ & $\begin{array}{l}\text { Wet sediment } \\
\text { NaCl saturated } \\
\mathrm{H} 2 \mathrm{O} 2 \\
\text { Filtration } \\
\mathrm{QA} / \mathrm{QC} \text { tests }\end{array}$ & $\begin{array}{l}\geq 10 \% \text { particles } \\
\text { Vibrational spectroscopy }\end{array}$ & $\begin{array}{l}\text { MP/mass } \\
\text { MP characteristics } \\
\text { (type, form, color, size) }\end{array}$ \\
\hline
\end{tabular}




\section{Introduction}

The discovery of plastic polymers began in the 1920s and 1930s and rapidly led to the invention of polyvinylchloride (PVC in 1920), polystyrene (PS in 1930), polyethylene (PE in $1933)^{1}$, resulting in the exponential production of new manufactured products which were rapidly adopted by $20^{\text {th }}$ century societies. Plastic production now increases by approximately 10 million tons each year, and reached 359 million tons in 2018, excluding production of polyethylene terephthalate (PET), polyamide (PA), and polyacryl-fibers ${ }^{2}$. More than 8 billion tons of plastic have been produced since $1950^{3}$, half of which for single use items ${ }^{4}$. While plastic waste collection and treatment vary strongly between countries, vast quantities of plastic waste are being globally mismanaged or are tossed inco ${ }^{1}$ andfills each year. Plastic dispersion into the environment is therefore of primary in nor ance ${ }^{5}$. MPs are defined as plastic items smaller than $5 \mathrm{~mm}$, whereas plastic items $h_{c}{ }^{+}$we : 5 and $25 \mathrm{~mm}$ and $>25 \mathrm{~mm}$ are categorized, respectively, as meso- and macroplas+ $\approx \mathrm{c}^{\circ}$. MPs are further classified into two size ranges including large MPs between 1 and $5 \mathrm{~mm}$. $\mathrm{d}$ small MPs of less than $1 \mathrm{~mm}^{7}$. For the classification of the lower size limit, there a ce $\mathrm{s}^{\wedge}$ veral propositions: $>1 \mathrm{~mm} ;>20 \mu \mathrm{m}$; > $1.6 \mu \mathrm{m}$ and $>0.1 \mu \mathrm{m}^{8-11}$. Although macrn- nd meso-plastics wreak dramatic deleterious physical damage including strangling or ${ }^{\circ}$ clusion $^{12}$, MPs have a potentially higher capacity to be ingested, transferred into food $\mathrm{w}_{\mathrm{h}} \mathrm{h} \mathrm{s}$, and finally to impact both organism physiology and ecosystem functioning due to their $s^{n} a_{1-1}$ size and high surface area. Two MP sources are identified including primary MP; thet include items used in cosmetics as well as raw MP pellets $^{13-15}$, and secondary MPs that originate predominantly from the fragmentation of larger plastic debris ${ }^{16}$. Numerous sturies dealing with the detection and distribution of MPs in aquatic systems have hec $\urcorner$ pr blished in the last decade.

The presence of $\mathrm{M}$ Ps in the environment has been reported from pole to pole and on all continents ${ }^{17,18}$, from air, terrestrial waters, oceans, sediments, and biota ${ }^{19-31}$. This indicates that all Earth's surface compartments have already been affected by the injection of MPs. Numerous studies in recent years on (i) MP toxicity due to the polymer itself or to the additives or adsorbed pollutants released, and on (ii) fragmentation mechanisms, are proof of the attention currently being paid to MP environmental issues by the scientific community ${ }^{32-}$ ${ }^{34}$. As the end-point of the plastic waste cycle, the marine environment has been widely studied. Around 10 million tons of plastic waste are dumped into the global ocean each year ${ }^{5}$. MPs have been found in seawater, in organisms ranging from zooplankton to fish, birds and turtles, in sandy and coastal sediments, as well as in seafloor sediments ${ }^{35-44}$. After reaching the ocean, many MPs sink in the water column after a change of density driven by physical, 
chemical and biological interactions ${ }^{45}$. Despite the fact that the sinking mechanisms of MPs in the marine environment are not yet fully understood, the majority of MPs by mass and quantity are found in sediments due to this change of density and/or to bio-interactions, and are subsequently found in high abundance in surface sediments (top $5 \mathrm{~cm}$ layer) ${ }^{46-49}$. However, there is a lack of conformity between studies concerning all steps of MP quantification in the sediment compartment: sampling, preparation, separation, extraction, identification and treatment of results. This study thus aims to review the various protocols used at each step when evaluating MPs in marine sediments, a compartment that can be likened to a large repository and reservoir of plastic debris. Recent reviews have focused on all sediment types (including lake, river and marine sediments) ${ }^{0-55}$. Based on 70 studies, we compared the various protocols used at each step and dis uss their advantages and shortcomings in the aim of harmonizing them to lead to res lts that are more comparable across the global ocean.

\section{Methodology}

Marine sediments, including ber the, coastal and deep-sea sediments, make up the compartment most affected by MP contamı tion, and studies on this topic will be the focus of this review paper. The 70 studi $w$ re selected from international journals using the following keywords: "microplasti " a " "marine sediment" on the Web of Science platform. All original papers including t ies, two keywords were examined before the selection. The papers were published from $2 i^{7} 4$ to March 2020. Four studies $(6 \%)$ were published in the 2004-2009 period, whilf $1: \%$ of the studies date from the 2015-2020 period. The papers come from 23 differenı : ournals, with most articles being published in the Marine Pollution Bulletin, Environmentaı Pollution, and Science of the Total Environment (27, 14 and 7 papers, respectively). Each study was reviewed carefully with particular attention given to methods of sample collection, MP extraction, MP identification and results reported. This critical review of this body of literature allows us to put forward recommendations and make suggestions concerning future research investigating MP contamination in marine sediments.

\section{Results and discussion}

\section{III.1. Sediment collection}




\section{III.1.1. Study areas}

We found that studies on MPs in marine sediments have been published in at least 70 articles, at a total of 813 locations on all continents, including Earth's poles (Figure 1). Areas studied are mainly in coastal environments, and the number of locations examined per study ranges from 1 to 72 . It is noteworthy that this topic is paramount in Europe (mainly in the Mediterranean Sea and the North Sea) and in Asia, which together account for $80 \%$ of the total studies, while in South America the subject area has not yet been closely investigated. In recent years, Asia has become a hot-spot of plastic pollution, and 8 of the 10 world's worst countries in terms of plastic waste disposal are Asian, including the top three polluters, which are China, Indonesia and the Philippines ${ }^{5}$.

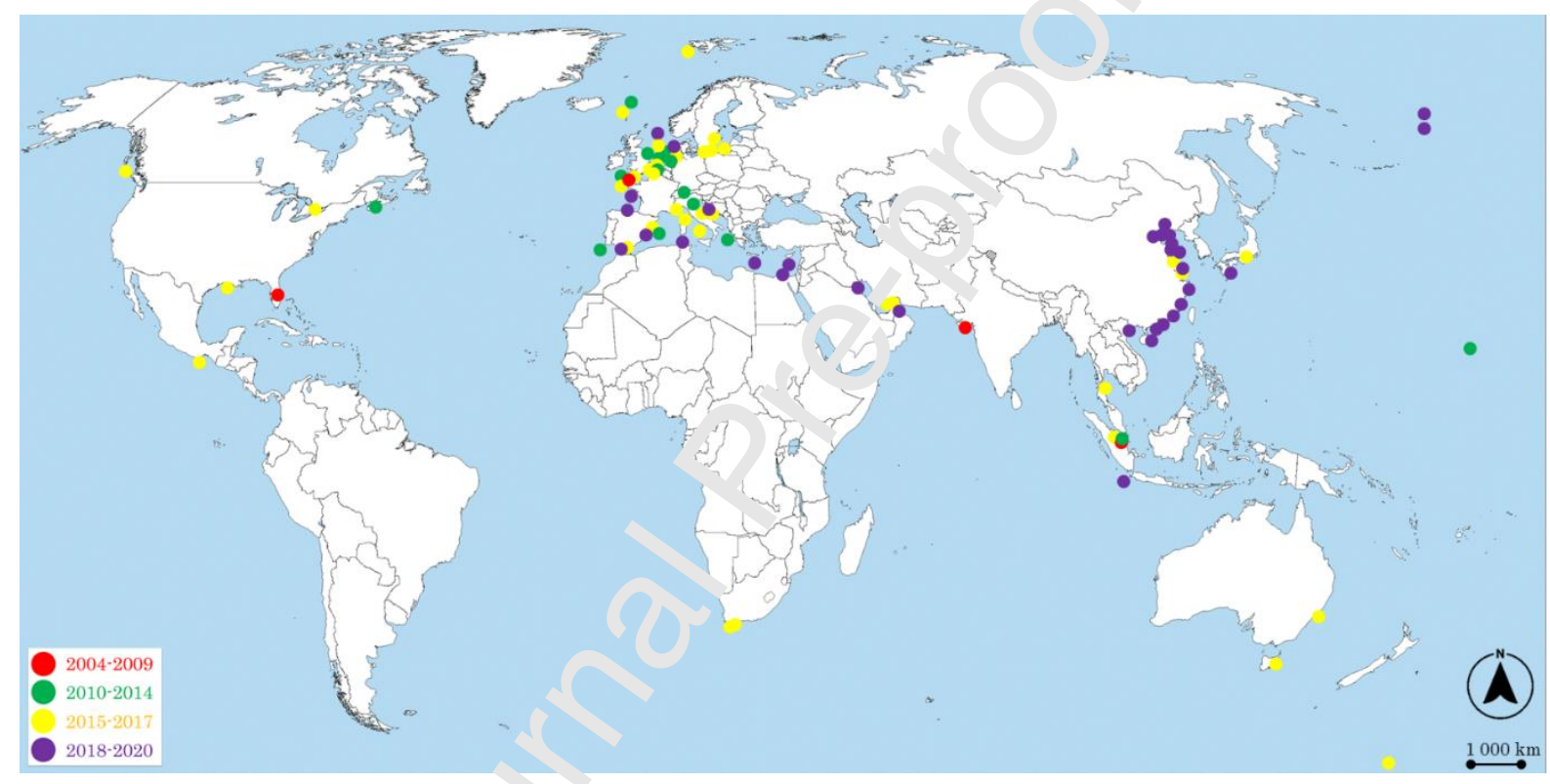

Figure 1: Stu? ${ }^{1} \mathrm{v}$ a eas for MPs in marine sediments, reported since 2004.

\section{III.1.2. Sampling and scorage}

Reports into open ocean bottom sediments (seabed, seafloor) represent $10 \%$ of studies, while the remainder of the studies focus on beaches and coastal areas. Sample collection protocols reveal a large diversity: depending on the type of sediment (seafloor, open ocean, coastal, beach) and on the research group, samples were collected with different numbers of replicates, with different surface collection areas and with steel utensils of different types. Indeed, seafloor MPs were usually sampled using equipment as diverse as box corer or Van Veen grabs, while beach and coastal-sediment collection was usually performed with quadrants, buckets, glass jars and sometimes with metal spoons. Sediment core samplers are appropriate for both sampling types. High quantities of MPs were found in the top layer of the 
sediment (up to 7000 items per kg of dry sediment), and while deeper layers were much less contaminated by MPs (seven times less in sediments from $38-40 \mathrm{~cm}$ than from $0-2 \mathrm{~cm}$ depth $)^{48}$, they contain important information concerning both temporal trends and degradation mechanisms ${ }^{49}$. Other factors were evaluated as potential drivers of MP distribution, such as wind driven accumulation on beaches, and proximity of waste disposal activities. Downwind areas seem to be more affected ${ }^{42}$, while human activities were revealed as high factors of MP contamination $^{56-58}$. The number of replicates sampled in each study depended strongly on the characteristics of the study area. Table 1 presents information on sample collection of the published studies. The main differences in sample collection include the quantity of sediment sampled, the number of replicates, and the depth. Two methou for sample collection were presented by Hidalgo-Ruz et al. (2012) $)^{59}$ : bulk and volume- edu ed sampling ${ }^{59}$. Their paper describes the use of a sieving technique which permits $t$, se sct the particle size during the sampling procedure. The first method (bulk samplino) afers to a procedure in which the

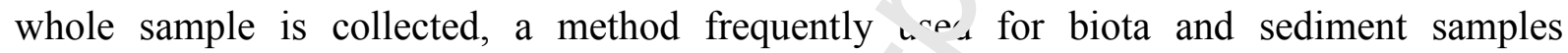
(including lake, river, sandy and marine sedimf at ). Regarding the 70 studies selected, only two were related to samples sieved in situ ${ }^{86,88}$ Voıume-reduced sampling with different mesh sizes was generally used for water samp ss, ince it permits to cover large areas. This method is also preferred for water samples, p tentially because of the lower quantity of MPs in water, as compared to sediments. Howev, r, he choice of sampling method also depends on the study objective (particularly ccannıng the target MP size). Direct sieving on site is sometimes undertaken for beac 'seciment samples (lower water content) when the MP size of interest is greater than $1 \mathrm{mr}$ : 


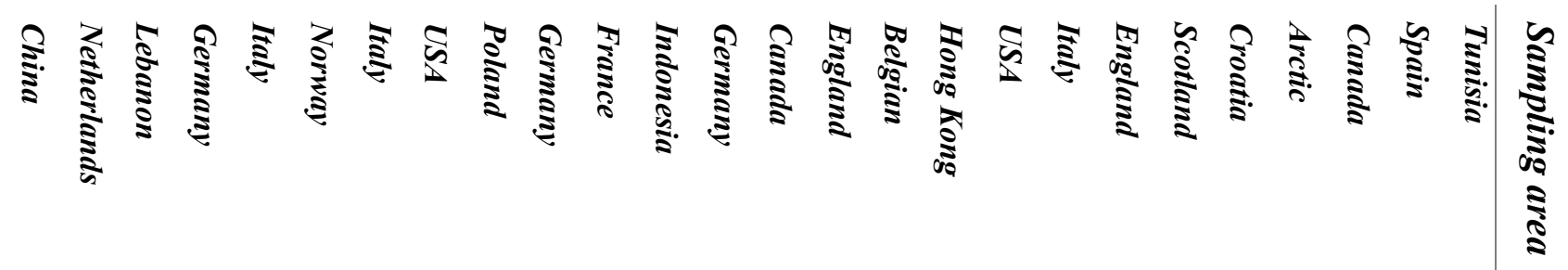

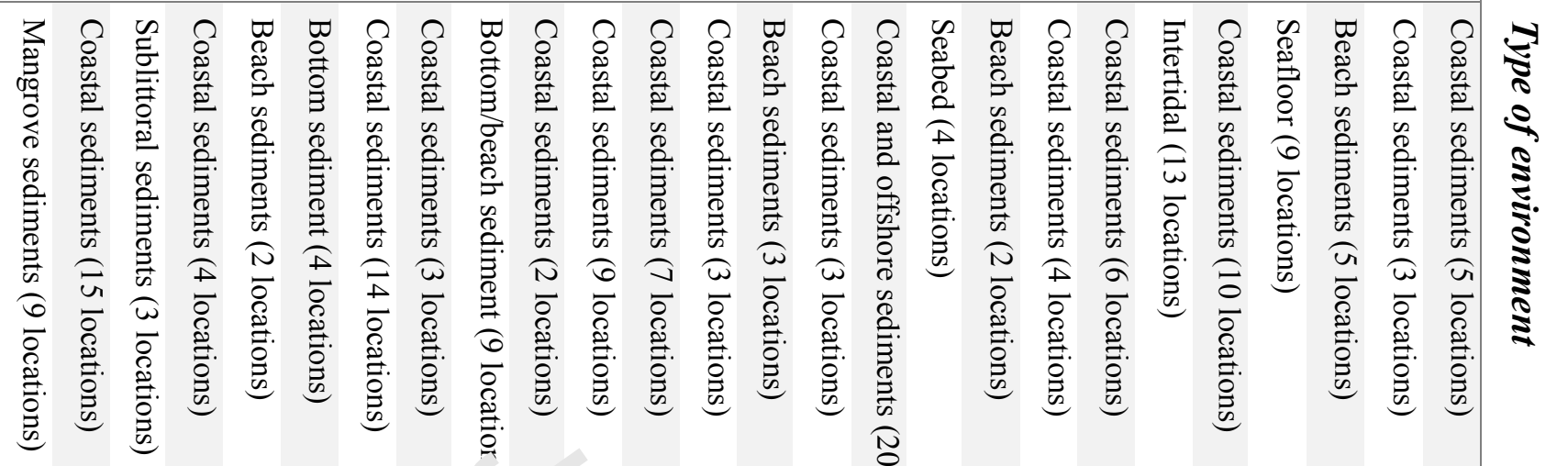
高

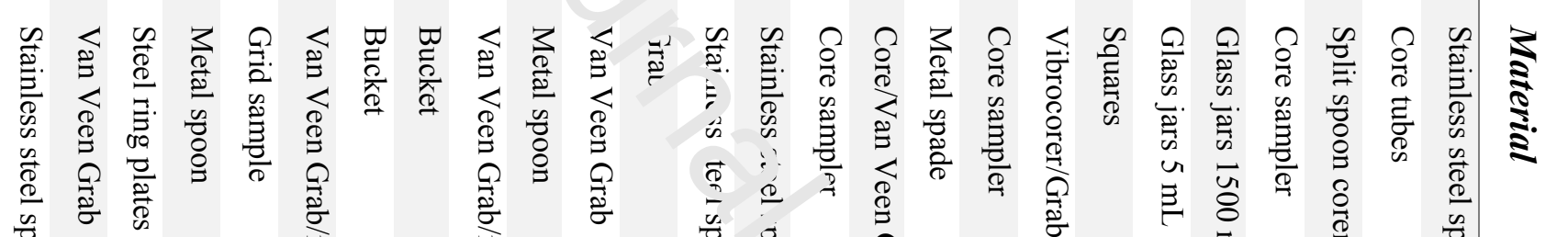
章 旁旁竞

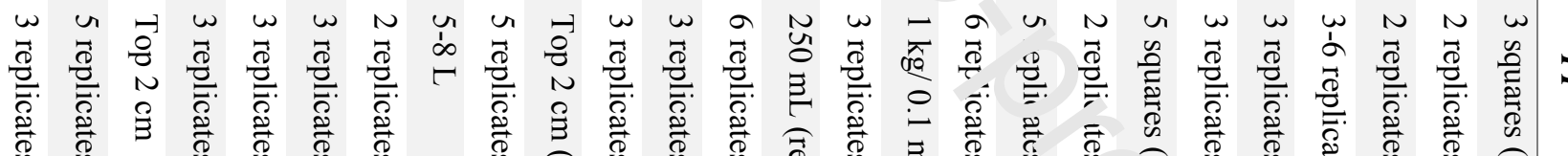

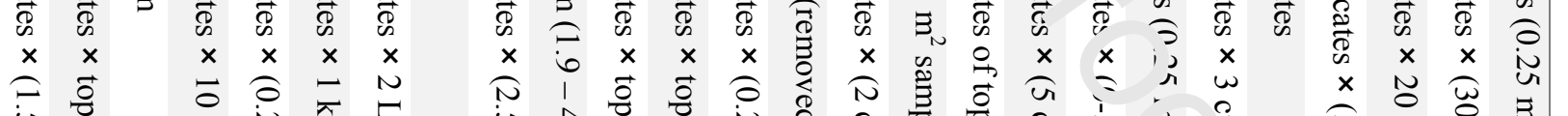

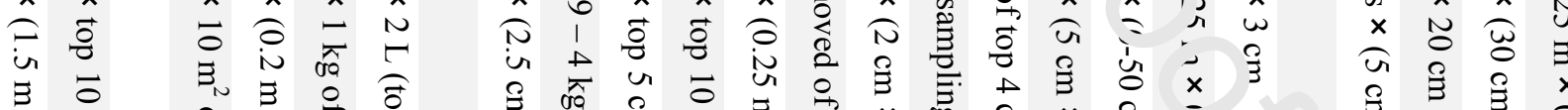

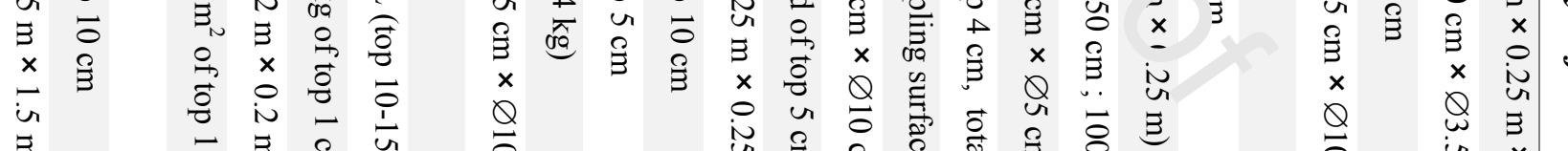

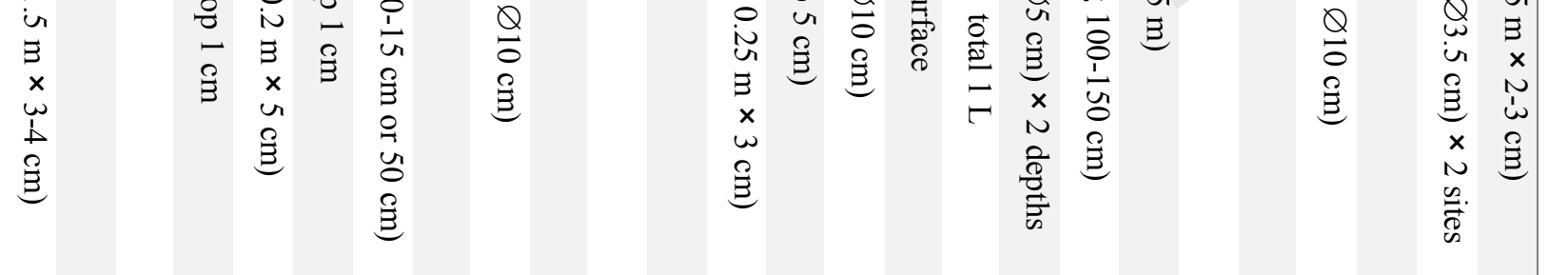

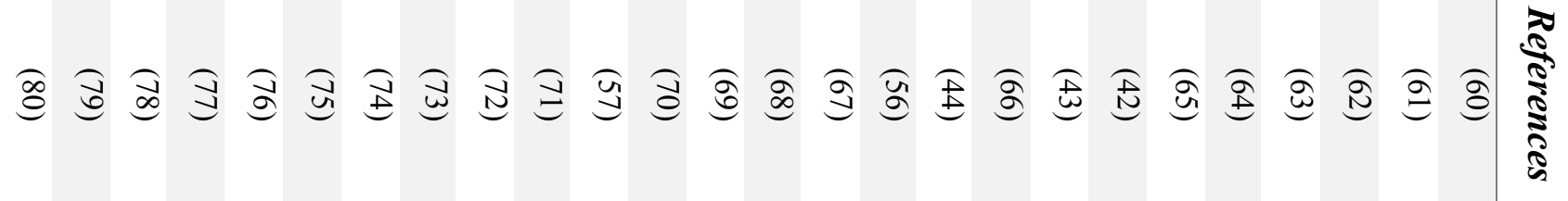




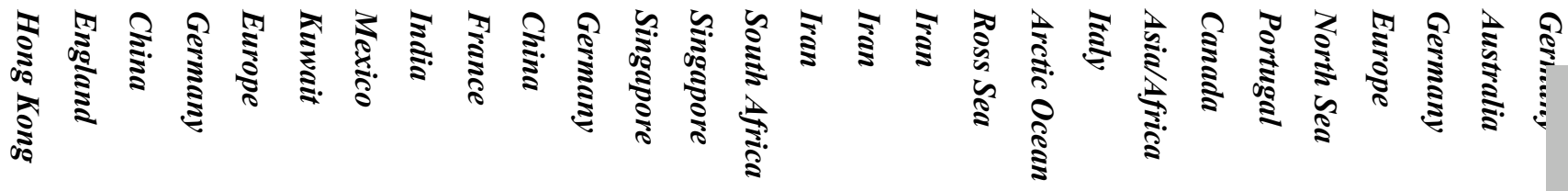

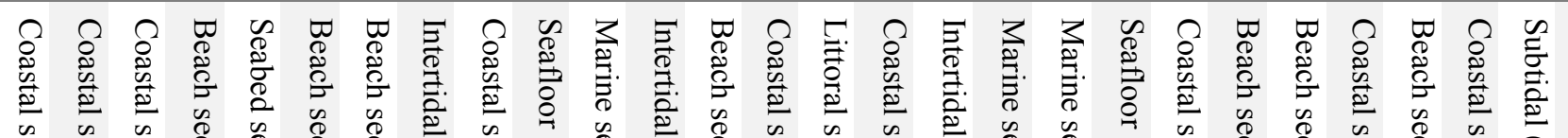

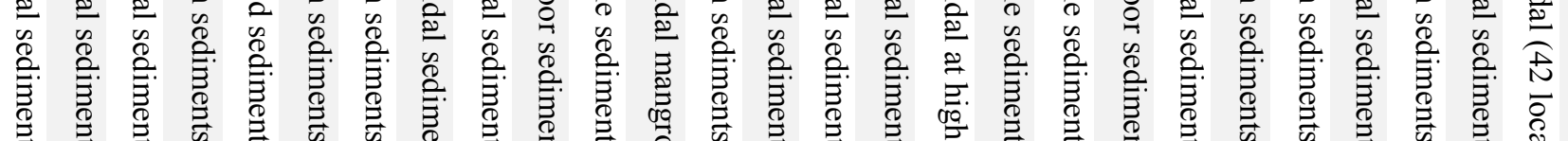

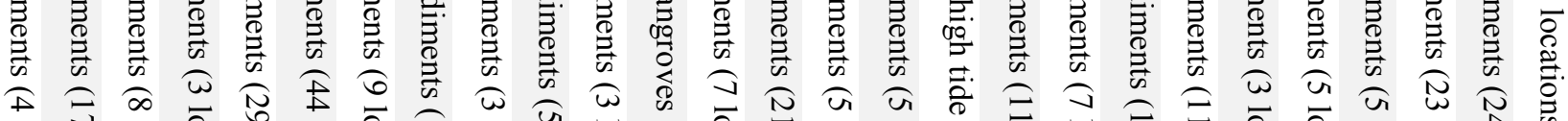

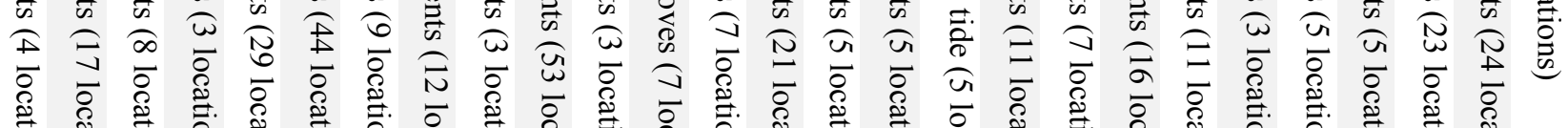

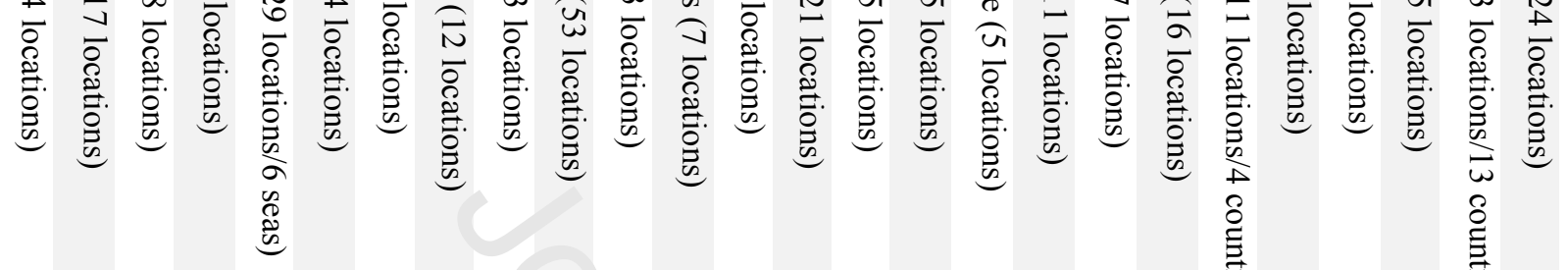

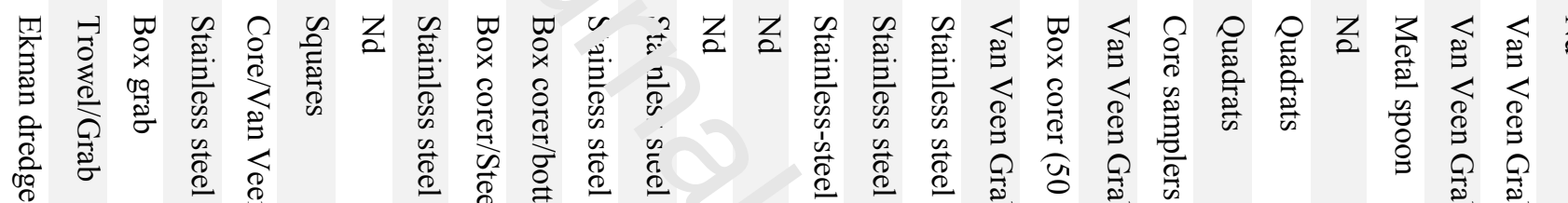

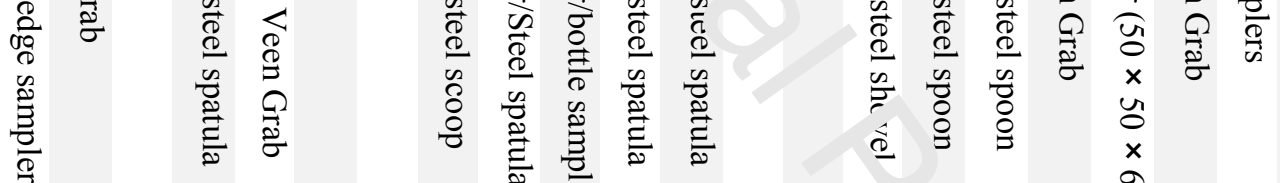
望咅

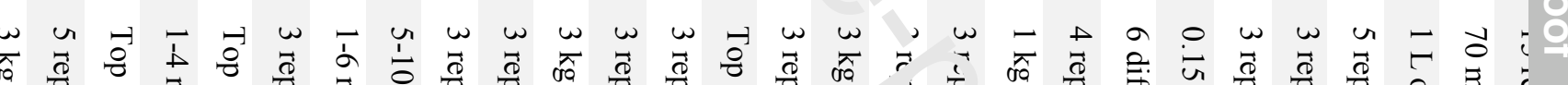
की

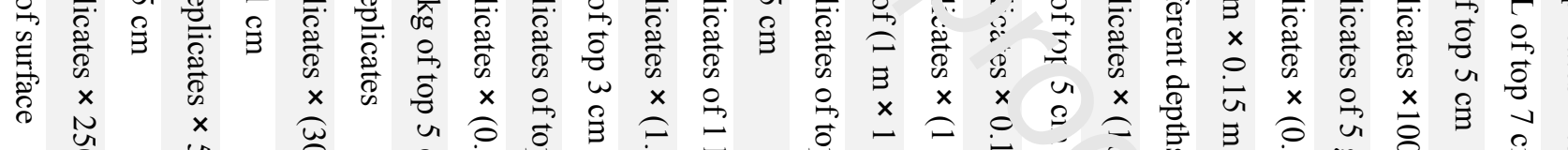

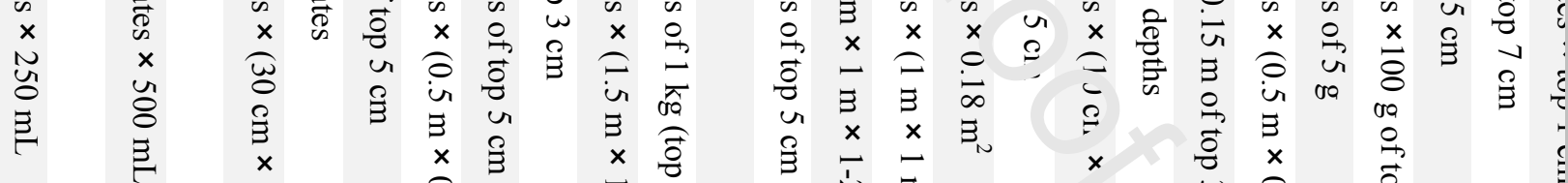

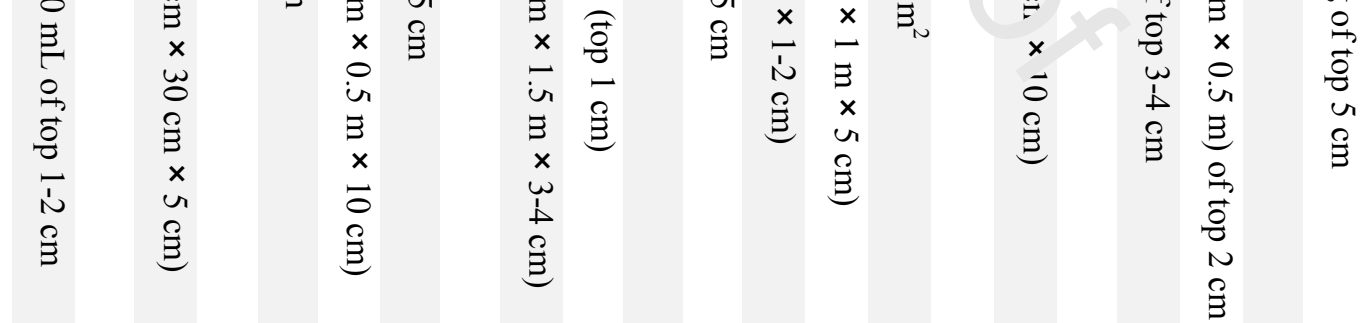

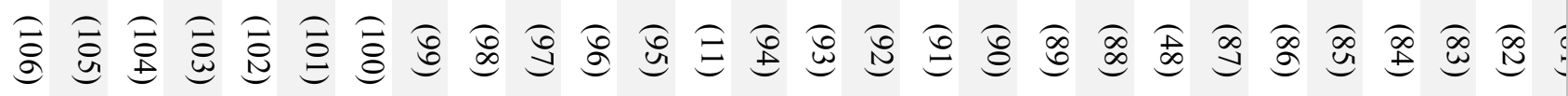




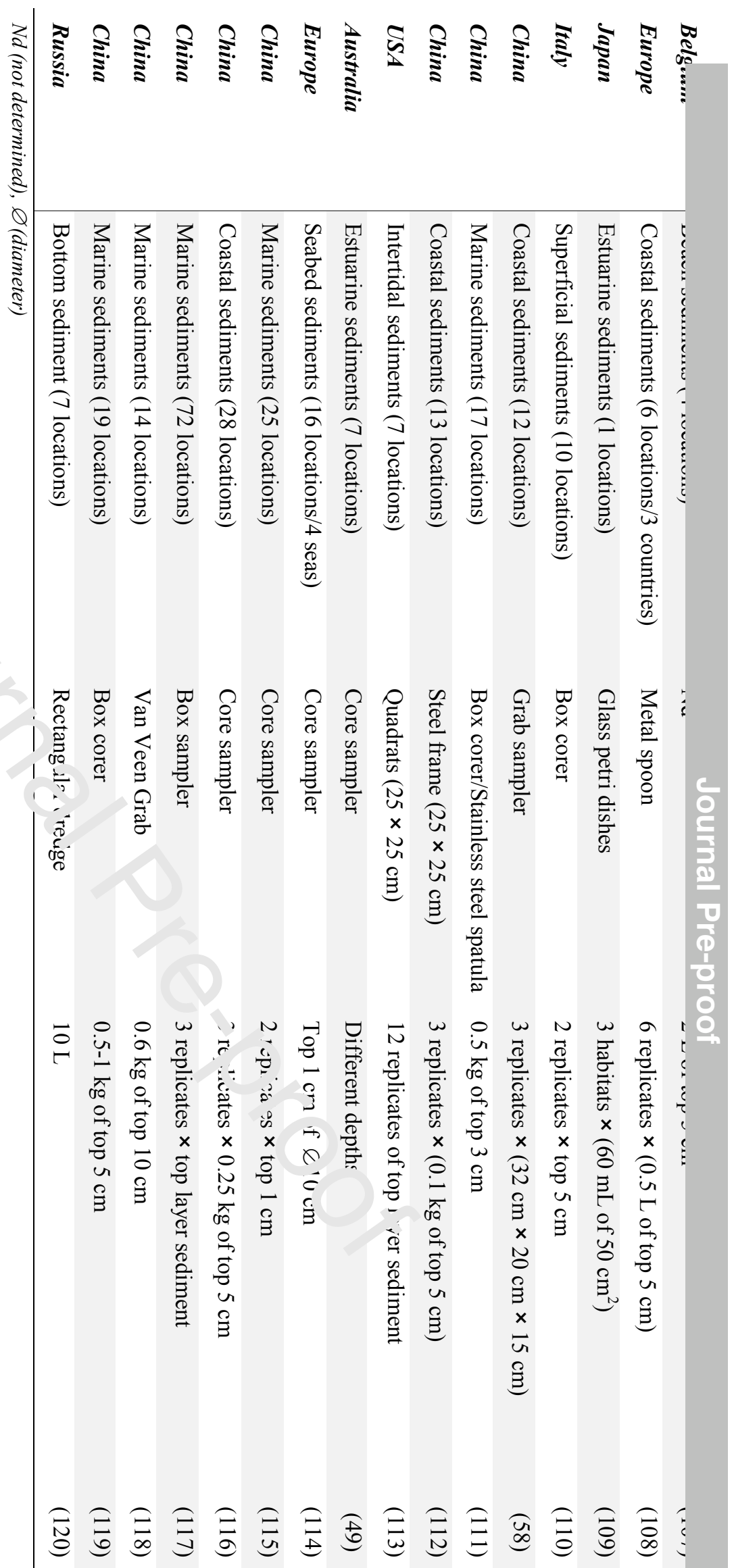




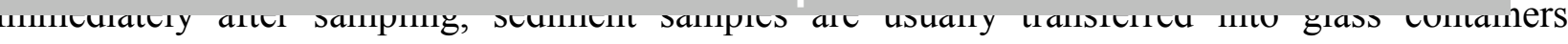

(bottles, jars), although plastic bottle storage has also been reported. They are then transported back to the laboratory at cool temperatures (i.e., kept in an ice box $)^{44,71}$, and are usually stored at cold temperatures in the dark, i.e., $-18{ }^{\circ} \mathrm{C} .{ }^{91-94}$ Storage duration before analysis was also variable, ranging from a few hours to several months. While none of the studies reported a degradation of MPs during transport and storage, high biofilm growth was observed during storage at room temperature ${ }^{68}$.

\section{III.1.3. Sampling and storage recommendations}

Sediment collection is the most important step when gathering representative data at each sampling site. An adapted sampling strategy must be considered, taking into account the selection of the sampling sites, the number of replicates, and the distance between sa nles and replicates. Studies on MP distribution (as a discontinuous variable), require the collection of $t$ les st five replicates at each location, with a minimum distance of $100 \mathrm{~m}$ between them ${ }^{121,122}$. Clean $\mathrm{s}$ eel sols (washed and rinsed with Milli-Q water) are strongly recommended for sediment sampling. Sec ments should be preserved in clean glass containers, placed at cold temperatures (around $4{ }^{\circ} \mathrm{C}$ ) and he apidly transported back to the laboratory. Storage temperatures must be respected until analysis. «n addition, we suggest that all sample information, for example, location coordinates, area covered viume and mass collected, depth and sediment characteristics (such as water content, organi $\mathrm{m}$.tter content, size distribution) should be gathered and reported in order to allow comparison with nther sudies. It should be noted that the transport and storage of sediment samples for subsequent an «1 is of MPs is similar to conditions required for organic compounds, which are subject to posis degradation by bacteria or to contamination by storage materials ${ }^{123,124}$. It is therefore prefe able to store these types of samples at $-20{ }^{\circ} \mathrm{C}$ in glass or metal recipients.

\section{III.2. MP Extraction}

Detection and quantification of MPs from sediment using physical or optical techniques requires preliminary steps of preparation including digestion, separation and isolation. Different reagents, materials used in each step are summarized in Table 2. 

sediments

\begin{tabular}{|c|c|c|c|}
\hline Operation & $\begin{array}{l}\text { Reagent } \\
\text { or material }\end{array}$ & Advantages & Drawbacks \\
\hline \multirow{3}{*}{ Digestion } & $\mathrm{H}_{2} \mathrm{O}_{2}$ & $\begin{array}{l}\text { Inexpensive, availability } \\
\text { Largest used, data comparable }\end{array}$ & $\begin{array}{l}\text { Instability } \\
\text { Loss of MP color observed } \\
\text { Boil intensely at high temperature } \\
\text { Adding slowly due to gas bubbles } \\
\text { during heated }\end{array}$ \\
\hline & $\begin{array}{l}\mathrm{H}_{2} \mathrm{O}_{2} \text { and } \\
\mathrm{Fe}^{2+}\end{array}$ & $\begin{array}{l}\text { Fast and efficiency } \\
\text { MP characteristics preserved }\end{array}$ & $\begin{array}{l}\text { Sharing drawbacks with } \mathrm{H}_{2} \mathrm{O}_{2} \\
\text { solution } \\
\text { Precipitation possible }\end{array}$ \\
\hline & Enzyme & $\begin{array}{l}\text { Highly efficient } \\
\text { No damage to sensitive polymers }\end{array}$ & $\begin{array}{l}\text { Time consuming } \\
\text { Complexity, } \mathrm{pH} \text { required }\end{array}$ \\
\hline \multirow{3}{*}{ Separation } & $\begin{array}{l}\mathrm{NaCl} \\
\text { saturated }\end{array}$ & $\begin{array}{l}\text { Availability and low price } \\
\text { Largest used, data comparable } \\
\text { Green method to the environment }\end{array}$ & $\begin{array}{l}\text { Lo ss of MP possible due to lowest } \\
\text { densi.y }\end{array}$ \\
\hline & $\mathrm{ZnCl}_{2}$ & High recovery & $\begin{array}{l}\text { E vpe sive } \\
\text { h. zardous to operator and } \\
\text { ar. vironment }\end{array}$ \\
\hline & $\mathrm{NaI}$ & $\begin{array}{l}\text { High recovery } \\
\text { Re-used possible }\end{array}$ & $\begin{array}{l}\text { Expensive } \\
\text { Sensitive to } \mathrm{pH}\end{array}$ \\
\hline \multirow{3}{*}{ Isolation } & Hand sorting & Simple and easy to & $\begin{array}{l}\text { Time consuming, experiment } \\
\text { required } \\
\text { Limited on MP large size }\end{array}$ \\
\hline & Sieving & $\begin{array}{l}\text { Rapidly } \\
\text { Easy to clean and ro ised }\end{array}$ & $\begin{array}{l}\text { MP size range still limited } \\
\text { Loss of small MP } \\
\text { Manually required later }\end{array}$ \\
\hline & Filtration & $\begin{array}{l}\text { Highly MP retain } \text { d } \\
\text { Diverse of fi te is are available } \\
\text { Largest us and comparable }\end{array}$ & $\begin{array}{l}\text { Depending strongly to digestion and } \\
\text { separation step } \\
\text { Filter type must be defined priory }\end{array}$ \\
\hline
\end{tabular}

The $\mathrm{H}_{2} \mathrm{O}_{2}$ solution was mos. used for organic matter digestion while the $\mathrm{NaCl}$ solution was predominant in separation step. B.th s vlutions permit to have data comparable to most of results reported. Filtration technique displayed rest esults to avoid small MP losses.

\section{III.2.1. Sediment pretreatment}

Quantities of sediment sample collected vary drastically among studies (Table 1). Generally speaking, only a portion of a sediment sample is used for MP analysis, depending on the volume collected, and pretreatment including sample homogenization, sub-sample selection, drying and sieving $^{122}$, is therefore necessary prior to MP extraction.

\section{a. Homogenization}

homogenization of samples aims to obtain uniformity so as to ensure that the sub-sample selected for analysis is representative of the entire sediment sample. Ten percent of the 70 studies selected mention this preparatory step. Of these, only two studies used a method involving mixing and stirring ${ }^{58,120}$. Once the sediment sample reaches room temperature, homogenization can be obtained using clean materials (i.e., stainless steel spoons). Due to the heterogeneous distribution of MPs in the sediment, 


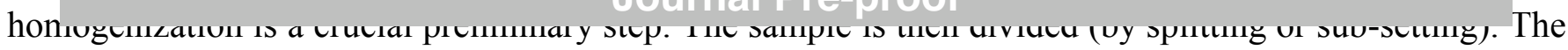

mass chosen for MP analysis (Table 1) depends on the objective of the study and the expected MP concentration.

\section{b. Drying}

Sixty percent of the studies were performed on dry sediment, while forty percent worked with wet sediment. Sediment drying provides a precise measurement of the quantity of MPs. Several techniques have thus far been adopted for drying the sediment matrix, with different advantages and drawbacks. First, the freeze-drying technique was reported in three studies ${ }^{48,79,106}$, and usually involved exposing sediments to very cold temperatures $\left(-50{ }^{\circ} \mathrm{C}\right.$ or even down to $\left.<-100{ }^{\circ} \mathrm{C}\right)$ and very low pressure for durations ranging from a few hours to several days, depending on the quantity of sediment and the depth of the sediment layer. Second, another sediment drying method Wa reported in 26 studies (37\%): this requires the heating of the sample to temperatures ranging from $5 r$ to $90{ }^{\circ} \mathrm{C}$ for durations ranging from 16 to 72 hours, depending on the sediment composition and, $m$ sre renerally, on the practices defined by the working groups based on their own experience. A third $\mathrm{t}_{\mathrm{r}}$ thod, involving drying in the air and sun, was also reported in a few other studies ${ }^{60,100-104}$. The adv ntą 2 of this latter method is to prevents MP degradation. However, its utility is limited to low $w^{\text {te }}{ }_{1}(<26 \%)$ content samples. Among these three drying techniques, freeze-drying is less used becau e . f ne need for more expensive apparatus, despite the fact that a porous sediment is obtained $\mathrm{W}$ ih the use of hot-temperature drying $\left(>60{ }^{\circ} \mathrm{C}\right)$, an additional milling step is necessary if sieving is to illow. Note that sediment milling may also lead to the fragmentation of MPs, although such bias $n^{\text {?s } ~ s o t ~ r e p o r t e d . ~ S i m i l a r l y, ~ t h e r m a l / s u n ~ t r e a t m e n t s ~ f o r ~ d r y i n g ~}$ sediment may provoke the thermo-oxi ${ }^{\prime}+i_{n}$ of MP particles, and therefore affect subsequent infra-red spectra, particle density, or other wea heing indicators ${ }^{45}$.

\section{c. Sieving}

The operation of sieviag is used to eliminate matrix particles and allows to obtain MPs of a specific size range. Approximı tely half of the studies (36/70) omitted a sieving step, while the other half applied different cutoffs, ranging from $25 \mu \mathrm{m}$ to $5 \mathrm{~mm}$ (metal or nylon sieves). The sub-sieving of sediment samples helps to determine MP concentration in each size class, therefore several sieve sizes may be used to fraction the sediment particles into different size categories ${ }^{61,82}$. This technique is highly efficient for MP fragments and pellets, but not for fibers or filaments. For example, a MP fiber exceeding $2 \mathrm{~mm}$ in length persisted after sieving using a $1 \mathrm{~mm}$ mesh $^{98}$. Sieving may thus be misleading, and furthermore, may be a source of contamination. However, taking into account the size definition of MPs, an initial sieving step at $5 \mathrm{~mm}$ seems necessary for the removal of larger items, while a second sieving at $1 \mathrm{~mm}$ is necessary to separate small and large MPs.

\section{III.2.2. Digestion}

The digestion step aims at removing the natural organic matter (NOM) from sediment samples. Indeed, the presence of organic matter hinders to filtration step and may lead to misidentification of 


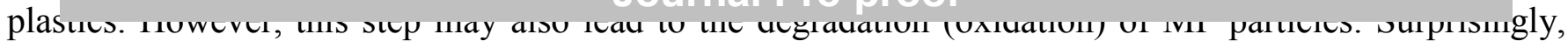
nearly $70 \%$ of studies did not include this step very likely due to the low organic matter content of the samples, involving a final filter clean enough for running the following steps.

Among the 70 studies, different reagents for the elimination of NOM were used, predominantly $\mathrm{H}_{2} \mathrm{O}_{2}(\mathrm{n}=14)$, followed by a mixture of $\mathrm{H}_{2} \mathrm{O}_{2}$ with ferrous ion $\left(\mathrm{Fe}^{2+}\right.$, Fenton's reagent; $\left.\mathrm{n}=6\right)$ and enzymes. Hydrogen peroxide $\left(\mathrm{H}_{2} \mathrm{O}_{2}\right)$ is an oxidizing compound, which is used not only for sediment samples but also on biota and surface water, since it is inexpensive and easy to work with ${ }^{127,128}$. In general, a concentration of $30 \%(\mathrm{w} / \mathrm{w})$ was used, while duration ranges were reported from 12 hours (overnight) to a week, depending on the organic matter content. ${ }^{49}$ A volume of $150 \mathrm{~mL}$ of $\mathrm{H}_{2} \mathrm{O}_{2}$ solution was added to 10 grams of sediment in Mathalon and Hill study, while only $5 \mathrm{~mL}$ were used for 50 grams of initial sediment in $\mathrm{Zhao}$ et al. ${ }^{87,117} \cdot \mathrm{H}_{2} \mathrm{O}_{2}$ seems more appropriate for sedi1. ?nt samples than acid or hydroxide reactants, although it also presents drawbacks such as instability $\mathrm{F}$.rtnermore, $\mathrm{H}_{2} \mathrm{O}_{2}$ was reported to discolor PA, PC and PP ( $>1 \mathrm{~mm})$ after 1 week $^{96}$. It should as ve noted that this compound boils intensely when heated above $75^{\circ} \mathrm{C}^{129}$. Strong differences a re uescribed depending on the volume of $\mathrm{H}_{2} \mathrm{O}_{2}$ used for sediment samples. These divergences ca be explained by the protocol used. Indeed, Mathalon and Hill (2014) ${ }^{87}$ added $\mathrm{H}_{2} \mathrm{O}_{2}$ directly to the sediment matrix, whereas Zhao and co-authors $(2018)^{117}$ conducted a separation step before the ac'd $d^{n}$. of the digestion reactant. Fenton's reagent (a mixture of hydrogen peroxide and ion $\mathrm{Fe}^{2+}$ ) we $;$ t11 st suggested by Masura et al. ${ }^{129}$. These authors reported the use of $20 \mathrm{~mL} \mathrm{H}_{2} \mathrm{O}_{2} 30 \%$ with $20 \mathrm{~mL} \mathrm{~F}^{2+} 0.05 \mathrm{M}$ for the removal of organic matter in water, beach and seabed samples. This reagent was in ore frequently used in the more recent articles. Its main advantage is that it reduces the digestior tin. 0 o less than one hour ${ }^{82}$.

Enzymatic digestion in sedir cen. samples was also reported, involving three different enzymes including protease, cellulose and $c_{1} \cdot{ }^{i}$ inase ${ }^{122}$. It should be noted that single enzymatic digestion was reported only once, whereas in. Illt-digestion (enzymes and $\mathrm{H}_{2} \mathrm{O}_{2}$ ) procedure was used by Lorenz et al. $^{75,83}$ This method was repo ' a to be highly efficient (>98\%) for the removal of organic matter using a variety of materials and chemical products and undergoing three principal steps of MP extraction (Figure 2, Table 3). The main advantage of enzymatic digestion is that there is no damage to sensitive polymers such as Nylon and polyester fibers ${ }^{125,126}$. However, this method is complex due to i) the use of surfactants for increasing the contact with enzymes, ii) the use of different enzymes, and iii) the use of buffers for $\mathrm{pH}$ adjustment. This method is therefore less often employed for sediment samples. 
Journal Pre-proof

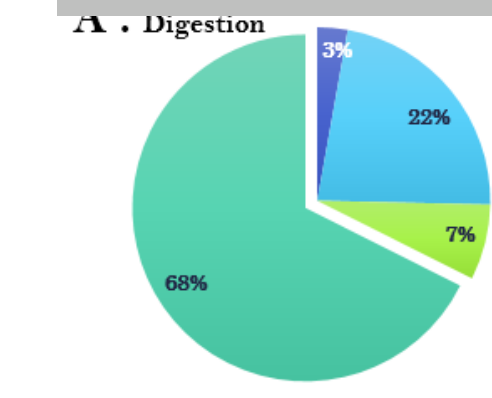

$=$ Enzyme $=\mathrm{H}_{2} \mathrm{O}_{2}=\mathrm{H}_{2} \mathrm{O}_{2}+\mathrm{Fe}^{2+}=$ Not Applied
D. Separation

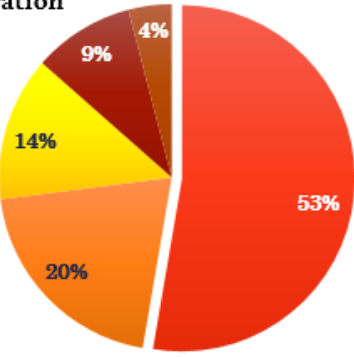

$\pm \mathrm{NaCl}=\mathrm{ZnCl}_{2}=\mathrm{NaI} \approx$ Others $\approx$ Not Applied
C. Isolation

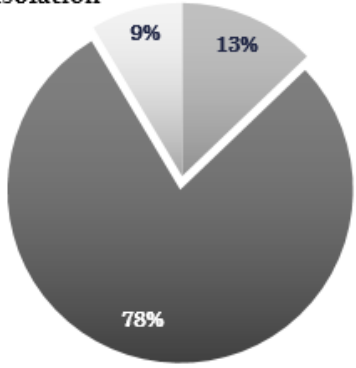

nieve - Filtration Not avaiable

Figure 2: Reagents and materials used for MPs extraction in sediments $(n=70)$, steps corresponding to digestion (A), separation (B) and isolation (C). 


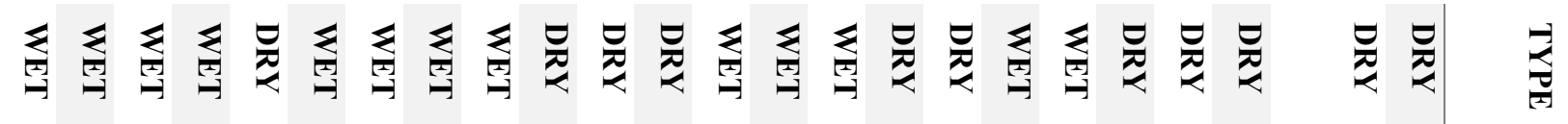

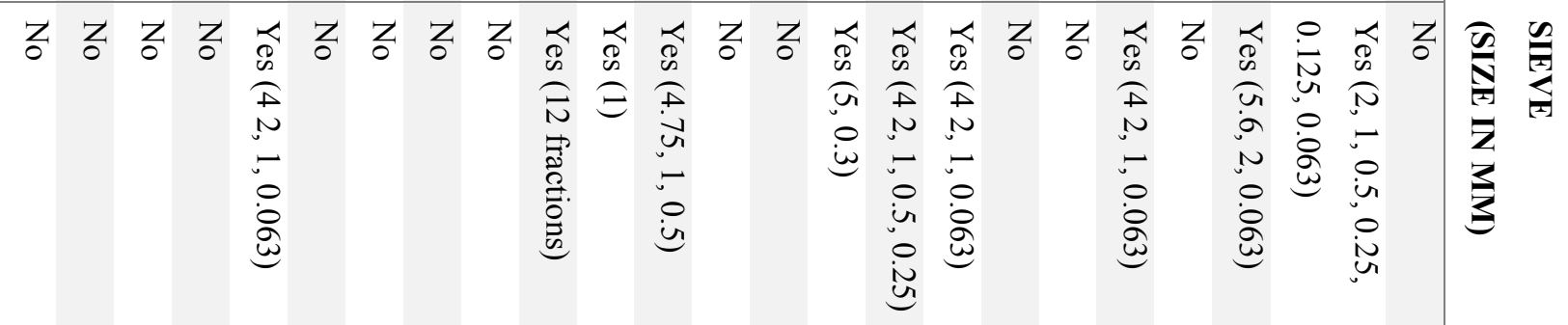

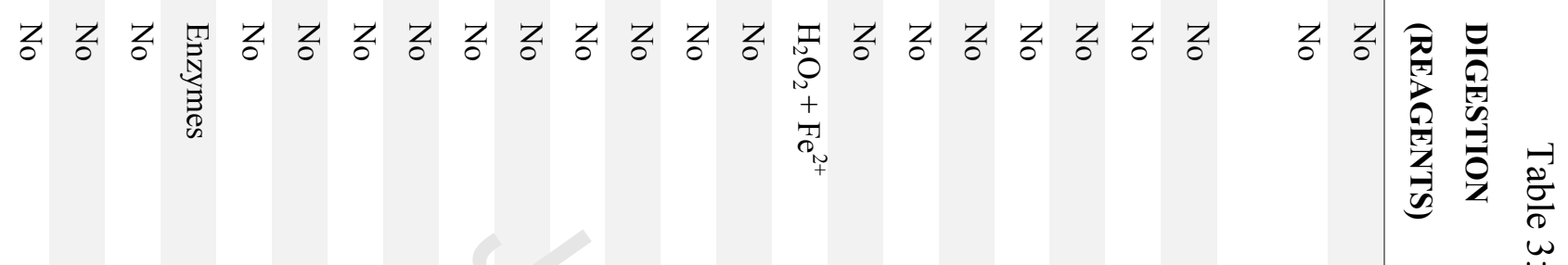

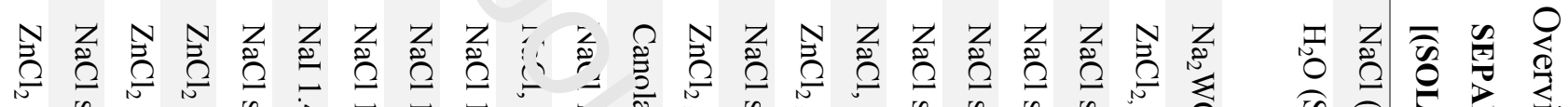

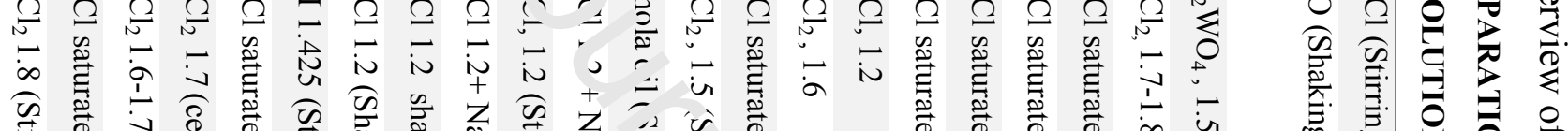

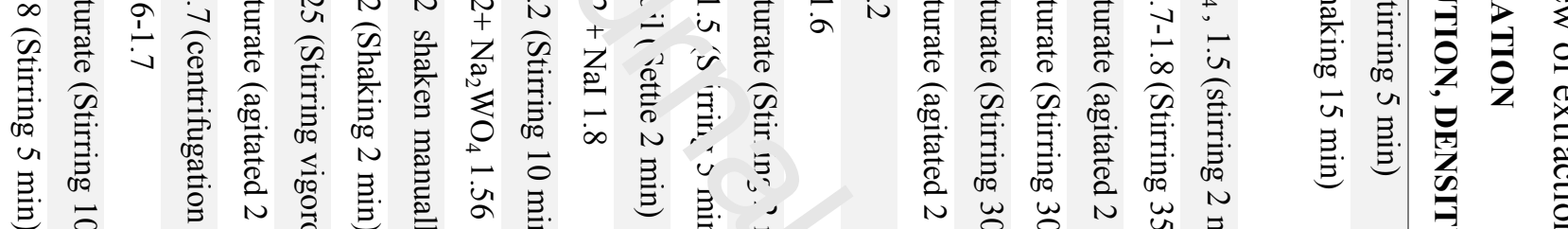

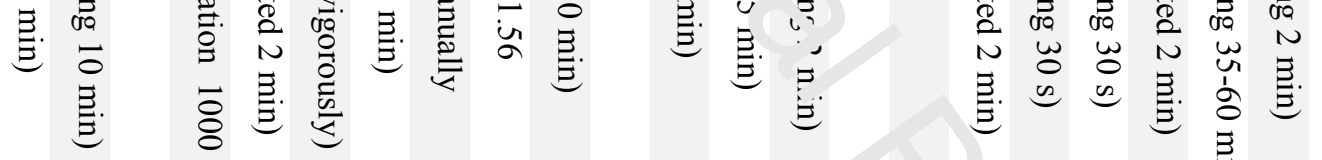

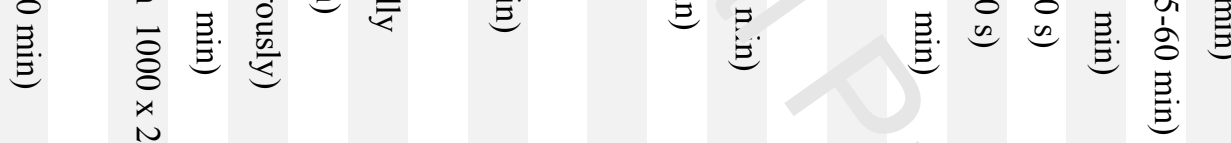
窝.

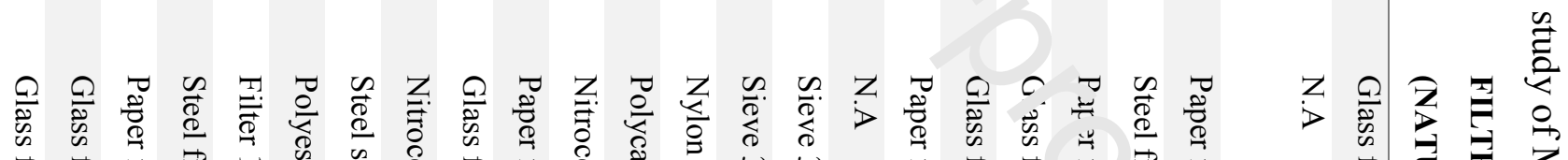

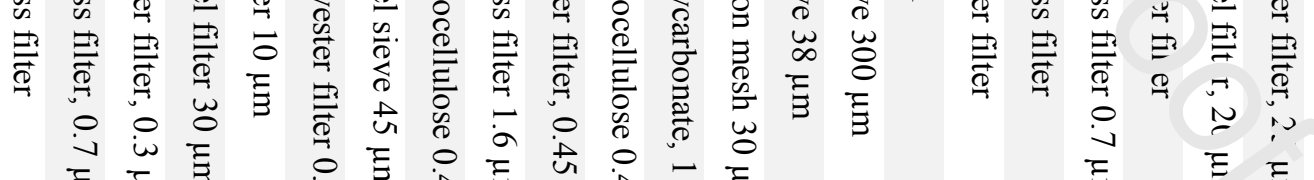

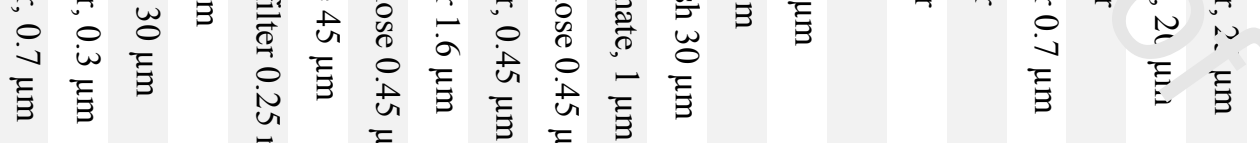

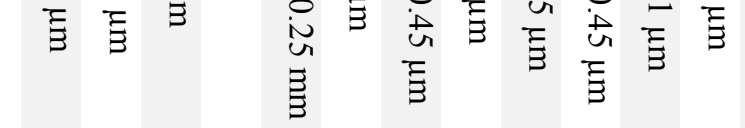

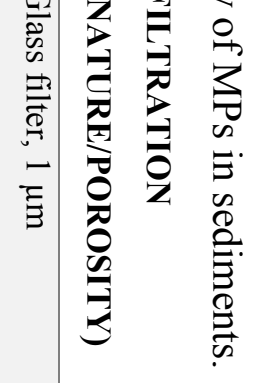

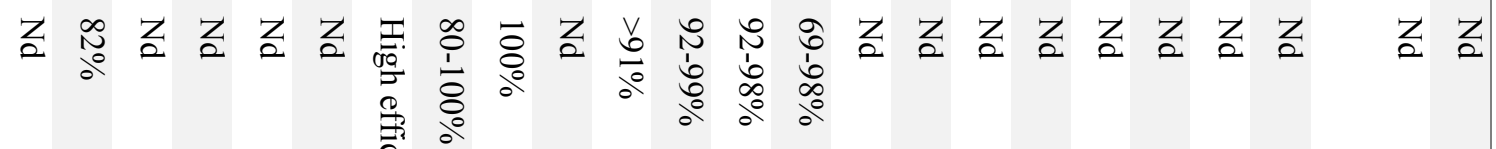

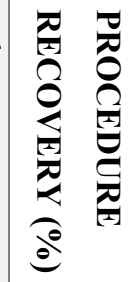

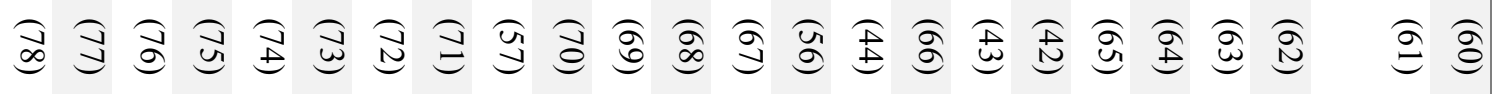




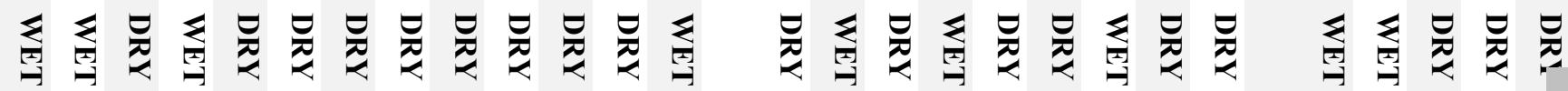

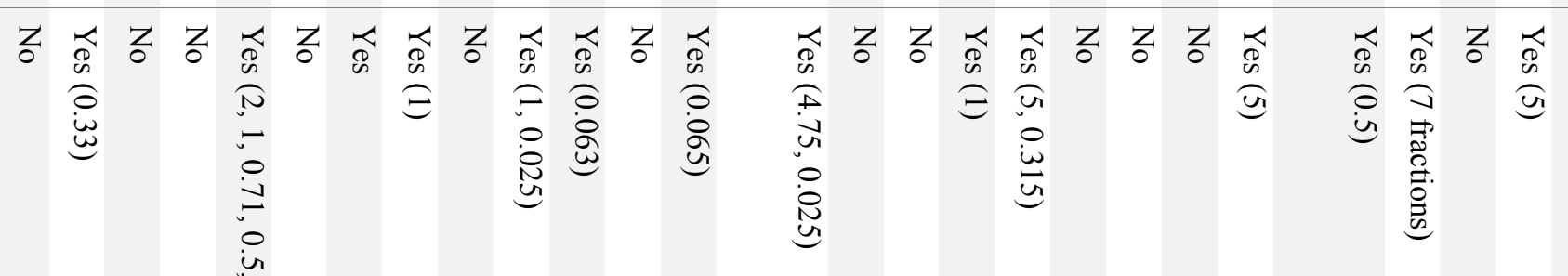

通

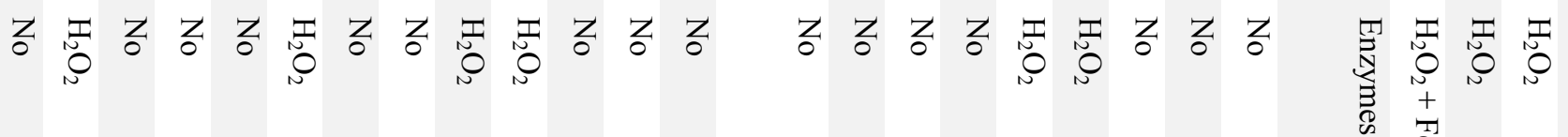

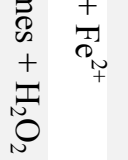

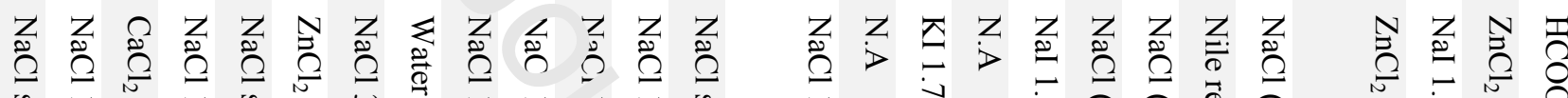

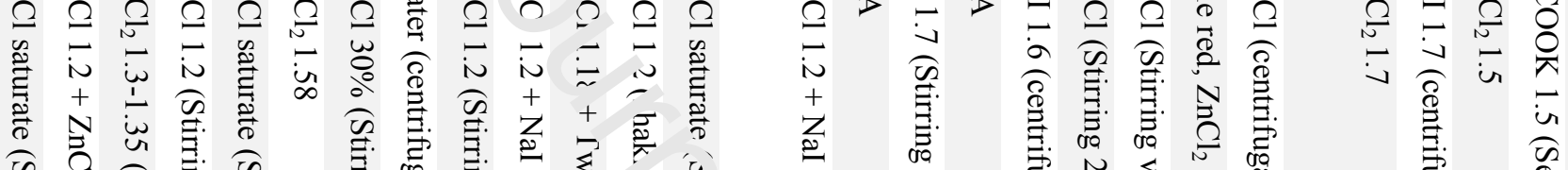
$\begin{array}{lllllllllll} & \\ 0\end{array}$

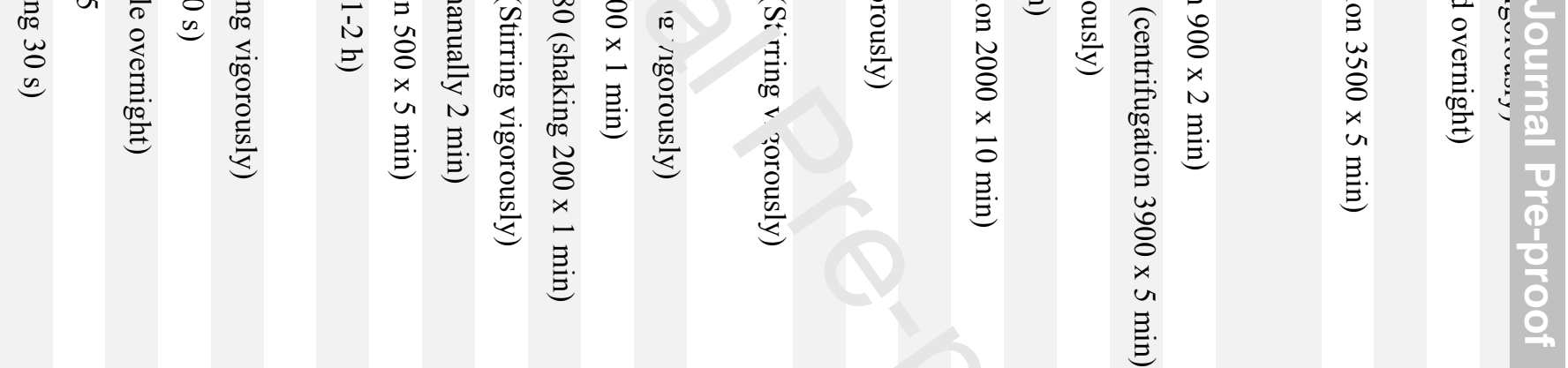

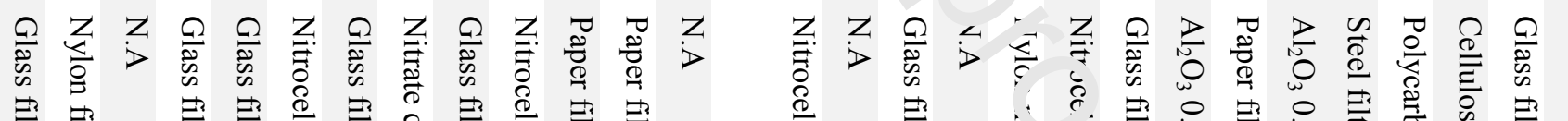

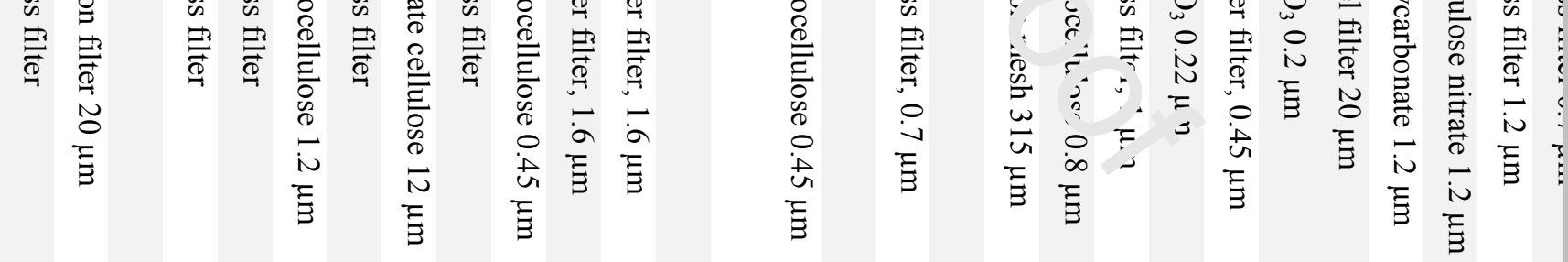

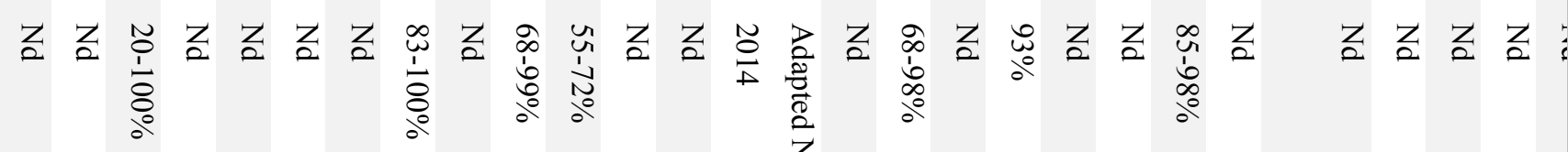

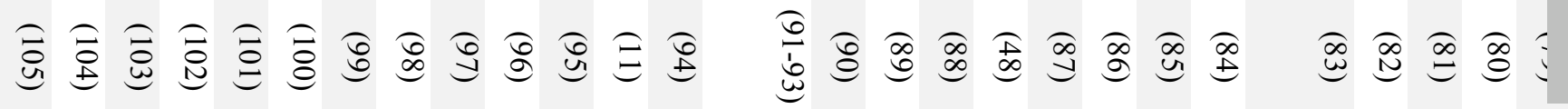




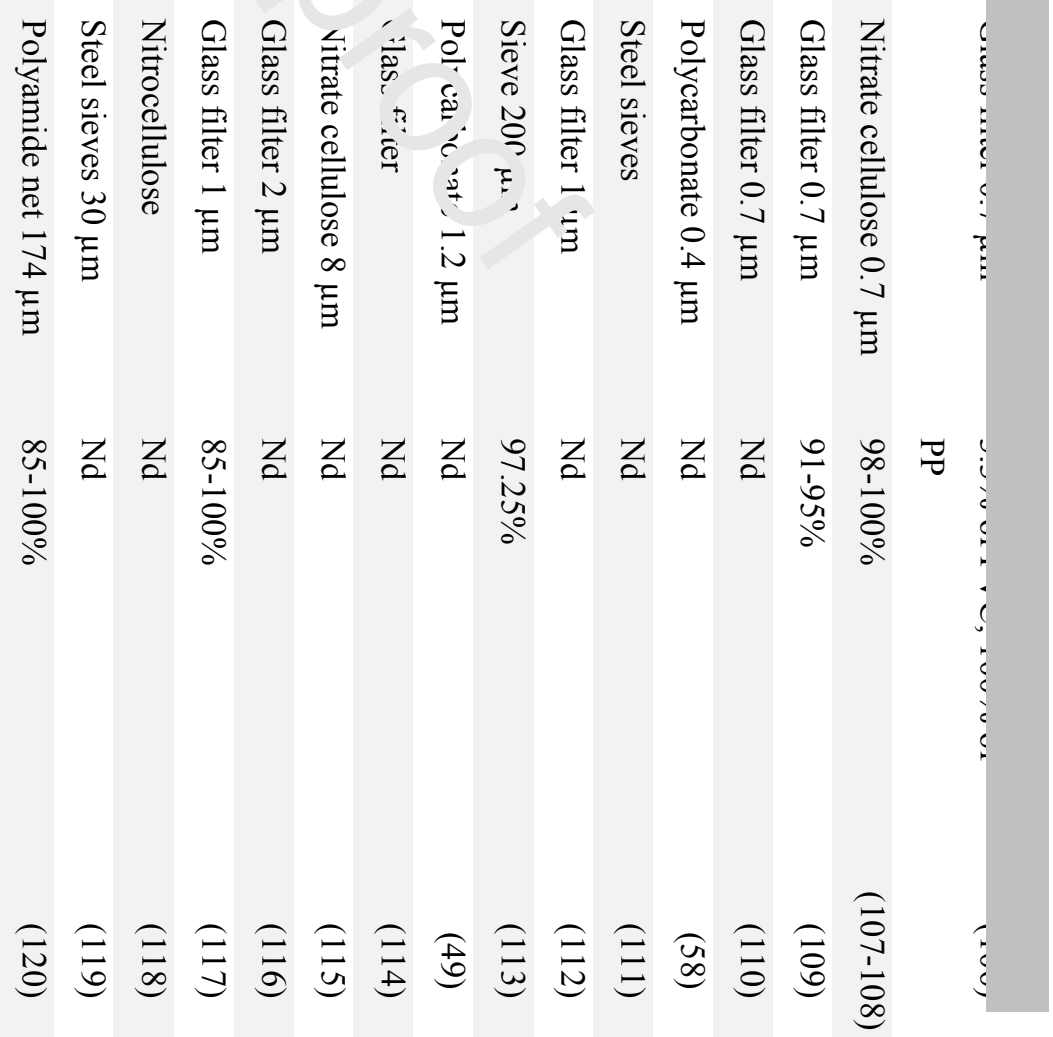




\section{III.2.3. Separation}

MPs must be separated from the sediment particles within the sediment matrix. Practically, sediment samples cannot be filtered because of the high quantity of sediment particles compared to MPs. A density separation step is thus usually performed (93\% of the studies) using solutions of different densities. The use of a dense solution (e.g., KI, $\mathrm{NaI}, \mathrm{ZnCl}_{2}, \mathrm{NaCl}$, etc.) allows to separate sediment particles (mean density $2.65 \mathrm{~g} \mathrm{~cm}^{-3}$ ) from MPs that are less dense than the chosen solution ${ }^{59}$. The authors most often recorded plastic density values ranging from 0.8 to $1.4 \mathrm{~g} \mathrm{~cm}^{-3}$.

Three solutions are mostly used for density separation: sodium chloride $(\mathrm{NaCl})$, zinc chloride $\left(\mathrm{ZnCl}_{2}\right)$ and sodium iodide $(\mathrm{NaI})$. Densities reported for these solutions are 1.18-1.20, 1.37-1.80, and 1.43-1.80 $\mathrm{g} \mathrm{cm}^{-3}$, respectively (Table 3). $\mathrm{NaCl}$ solution has less variation considering its density value, which explains why it is often used at saturation, which is around $3 \mathrm{~s}^{\circ} \mathrm{g} \mathrm{L}^{-1}(\mathrm{w} / \mathrm{v})$ at $20^{\circ} \mathrm{C}$. Only two studies used $\mathrm{NaCl}$ solution at lower concentration $\left(140 \mathrm{~g} \mathrm{~L}^{-1}\right)^{60,86}$. Den ,ity was more often reported than concentration units, but these values are convertible depending on 1 smperature. The main advantages of $\mathrm{NaCl}$ utilization are its availability and low price. The shortmning of $\mathrm{NaCl}$ is its low density, enabling to recover only some types of plastic polymer present in the al. 2017) ${ }^{130}$. The use of denser solutions, such as $\mathrm{ZnC}, 1_{2} \mathrm{NaI}, \mathrm{CaCl}_{2}, \mathrm{Na}_{2} \mathrm{WO}_{4}$, and $\mathrm{KI}$ allows to recover denser plastic polymers, such as PVC $\left(\mathrm{d}=1.16-\div 58 \mathrm{~g} \mathrm{~cm}^{-3}\right)$, PET $\left(\mathrm{d}=1.37-1.45 \mathrm{~g} \mathrm{~cm}^{-3}\right)$ and some fluoropolymers $\left(\mathrm{d}=1.7-2.2 \mathrm{~g} \mathrm{~cm}^{-3}\right)\left(\text { Kedzier }^{\prime}{ }^{\prime} \mathrm{i} \text { it al. 2017) }\right)^{130}$, in addition to other particles from the sediment which may potentially interferc with the visual determination during the following step. However, these solutions also present so ae ${ }^{1}$ rawbacks, for example $\mathrm{ZnCl}_{2}$ is known to be a hazardous compound, $\mathrm{CaCl}_{2}$ is very viscous and $\mathrm{I}_{\mathrm{a}} \mathrm{a}_{\mathrm{s}}$ expensive and sensitive to $\mathrm{pH}$ less than $6.5^{130}$. Kedzierski et al. ${ }^{130}$ developed a protocol to re-use ${ }^{2}$ ' $\mathrm{I}$ up to 10 times in order to lower the overall cost. Sedimentation is subject to complex processes, pa ticl iarly for small particles which are influenced by surface tension, physical and chemical proner ies, during which MP particles may interact rapidly with proteins, ions, micro-organisms, pollutants, le, ding a novel buoyancy to the aggregates that include MPs. The recovery of all MP types thus remains a difficult methodological challenge.

Many types of laboratory recipients were used for the MP separation steps, such as funnels, jars, Erlenmeyer flasks, beakers and tanks. All were made of glass, which is crucial when studying MPs. Surprisingly, some plastic equipment occasionally figures amongst the materials used, for example, centrifuge tubes made of PP or PTFE, a Sediment Microplastic Isolation (SMI) made of PVC, or an elutriation column made of $\mathrm{PVC}^{67,107}$. Given the breakdown of plastic materials, the use of these materials must be avoided for MP studies. Although these plastics are considered to be stable, Haave et al. recently detected Teflon and silicone when using a MicroPlastic Sediment Separator (MPSS) for MP separation ${ }^{75}$. MPs were separated principally using three mechanisms: flotation, elutriation and fluidizationflotation $^{96,105,107-108}$. However, as outlined above, elutriation columns and other separators (MPSS, SMI) are made of plastic materials. In the work presented by Nuelle and co-authors, high recovery rates were 


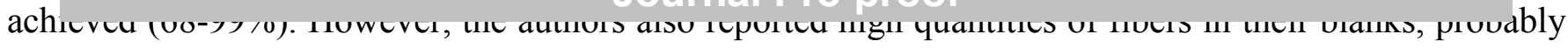

from cross contamination due to contact with air ${ }^{96}$.

To begin density separation, sediment and solution are mixed together, with a ratio volume/mass dependent on the density of the solution used. $\mathrm{A} \mathrm{NaCl}$ solution was added to the sediment with ratio ranging (v/w, dry weight) from one to ten ${ }^{48,70}$, while $250 \mathrm{~mL}$ of a NaI solution was added to 300 grams of wet sediment ${ }^{119}$. To ensure the mixing and contact of the sediment particles with the solutions for density separation, several techniques can be used: mixing with a steel spoon or glass rod, hand shaking, or stirring. In general, only several minutes were reported. The whole solution is then left to settle for periods of 1 to $48 \mathrm{~h}$ to ensure full separation. In order to save time, some authors performed a centrifugation technique $(\mathrm{n}=10)^{99,118}$, lasting 1 to $5 \mathrm{~min}$ (except Haave et al.) ${ }^{75}$, with different speeds ranging from 500 to 3900 revolutions per minute. We noted that the antrifuge tubes were made of plastic and that loss and fragmentation of MPs were reported by Haave et $2 .{ }^{-5}$

Once settling had occurred, the recovery of the superns an+ Iraction was seldom reported. Most studies specify that the surface layer was collected, anc sometimes indicate the precise volume recuperated, but they fail to describe the techniques used. Bec. use sediment particles can easily become re-suspended, we thus recommend that the surface fraction be cullected slowly, using a glass pipette or an overflow technique ${ }^{87,109}$. Either way, the tools used $(\mathrm{k} \cdot \mathrm{k} \cdot \mathrm{rs}$, tubes, Erlenmeyer flasks) need to be set up so that they slope, and must be well-rinsed aft r e ich use (MPs have a high attraction to glass surfaces). The separation step was often repeated several imes consecutively, usually between 2 and 5 times. Hydrophobic solvents were used to separatc MPs from the sediment matrix depending on surface properties. Crichton et al. $(2017)^{68}$ presente 1 .n oil extraction protocol using only $5 \mathrm{~mL}$ canola oil for 50 grams dry sediment. A high recovє :y ate was reported $(>95 \%)$, but the protocol requires a careful cleanup step of recovered MPs, L'aause small traces of oil can influence the subsequent optical identification. Favorably, the $\ddot{n}$ : cumpatible with all filter types. Organic, lipophilic stains can also be used to separate MPs from saiments depending on their surface properties, and can also be used for water samples ${ }^{131,132}$. The use vi Nile Red ${ }^{(85)}$ facilitates MP counting and observation using fluorescence properties $^{85}$. Different stain types, concentrations and incubation times were tested ${ }^{85}$, with reported recovery rates ranging from 85 to $98 \%$. However, the shortcomings of this method are that neither color nor composition can be determined after staining, as the stain also interacts with the biological matter in the sample.

\section{III.2.4. Isolation}

MP isolation aims at separating plastic particles from the environmental matrix. To do so, three techniques were usually chosen: hand sorting, sieving and filtration (Fig 2C).

Hand sorting is the most straightforward technique of the three, and was used in 6 studies of the 70 selected studies. Sample processing consisted in manually removing the target particles from dry sediment or from the surface of supernatant water ${ }^{58}$. However, this method presents sizeable 
particles larger than $1 \mathrm{~mm}$ and Munari et al. ${ }^{90}$ hand sorted large plastic items (large-MPs, meso- or macroplastic waste). The authors reported a size range of plastic waste from 0.3 to $22 \mathrm{~mm}$, with a predominant size range of $2-3 \mathrm{~mm}$.

Sieving was used in 9 of the 70 studies examined. This technique permits to retain plastic particles and to eliminate the aqueous matrix as well as small particles, depending on the selected sieve cutoff. The sieves used were usually made of stainless steel, nylon and polyamide with pore sizes ranging from 30 to $315 \mu \mathrm{m}$. Sieving in these nine studies was performed on supernatant water resulting from density separation, but we note that it was used for both wet and dry sediment, and that several sieves could be used sequentially on a single sediment sample. Large pore size ( $>1 \mathrm{~mm}$ for example) and sieve diameter allow to process high sample volumes. Sieves are easy to clean with filtered water and can be re-used for a batch of samples. However, the sieving technique presents $\mathrm{cW}$, shortcomings: first, sieving is appropriate for a limited size range only (large particles in gen $f_{\perp} a_{i}$, auwn to $30 \mu \mathrm{m}$ ), a constraint, which leads to a loss of size fractions of interest when studying MPs. Anutner drawback of the sieving technique is that MPs are not readily available for identification, so ${ }_{1}^{n}$ 'astı : particles must subsequently be manually identified.

The filtration technique combined with pumrin.; is a rapid step that was preferred when the target size of MPs was small. Different types of filt $r_{i}$ c mpusition were used: glass, cellulose, polycarbonate, polyester, steel, aluminum oxide, and nylon, wih filter porosity varying from 0.2 to $30 \mu \mathrm{m}$. Filter diameter varied to a lesser extent (often $13,2 \mathrm{\nu}, 47$ or $90 \mathrm{~mm}$ ), which required the adaptation of the glass filtration system. We noted that filters of (..' ' m were used in 55 of the studies on marine sediments. The two most used types of filter $\left(n=22 \mathrm{f} / \mathrm{r} /{ }^{\mathrm{x}} \mathrm{ch}\right)$ were glass fiber and cellulose filters (including nitro, nitrate and paper filters). Glass fiber filtc $: s$ iave the advantage of being available for many identification techniques and can be pre-cr.a.'lsued to avoid any contamination of the sample ${ }^{133}$. However, their retention size is small ( $0.7 \mathrm{t}$ l.v $\mu \mathrm{m}$ among reports) which thus limits the volume of the sample being analyzed. For this reason, sevual filters could be used for the same sample. Cellulose filters have greater porosity than the retention size of glass fiber filters $(0.3 \mu \mathrm{m}$ to $25 \mu \mathrm{m})$, but they absorb the laser signal during spectrum measurements in transmittance mode (FTIR technique). Moreover, they cannot be combusted before use to avoid any contamination. Polycarbonate and aluminum oxide filters have low porosity (0.4-1.2 $\mu \mathrm{m}$ and 0.2 , respectively), and, like glass filters, have the disadvantage of restricting the quantity of sample that can be analyzed. Steel filters have high porosity $(20-30 \mu \mathrm{m})$ but are not widely available. Polyester filters have even higher porosity $(250 \mu \mathrm{m})$, which may, nevertheless, be too high for the study of MPs, according to Graham \& Thompson ${ }^{73}$. A combination of different filter types was tested by Lorenz et al., who associated filters with two pore sizes $(0.2$ and $20 \mu \mathrm{m})$, which permitted a higher recovery of $\mathrm{MPs}^{83}$. After filtration, the filters were removed, enclosed in glass or plastic petri dishes, and dried at room temperature, or oven-dried up to $55^{\circ} \mathrm{C}^{64,106}$, before analysis. Closed conditions are 


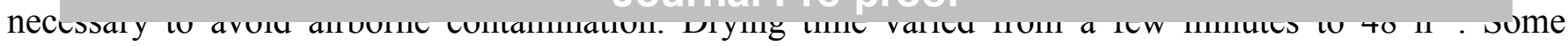

studies used thick-filters and high drying temperatures ${ }^{111}$, but this may damage the plastic polymers and is therefore not recommended.

\section{III.2.5. Quality Assurance and Quality Control}

MPs are omnipresent in the environment and quality assurance (QA) and quality control (QC) are thus necessary in MPs studies to prevent sample contamination, and identify it if it occurs. More than $70 \%$ of the studies avoided MP contamination by using clean tools as well as by respecting protocols concerning conditioning, storage and laboratory blanks. For example, laboratory equipment was washed and rinsed (one to three times) with clean water (double-distilled, demineralized or ultrapure), solvents and solutions were filtered before analysis in the closed fume hood (prewashed with ethanol 70\%). Samples were protected with aluminum foil to prevent airborne conımination and/or operators were wearing cotton lab coats and gloves at all times during the $a_{\llcorner} q 1 \mathrm{v}$,is. Airborne contamination was identified as the main source of sample contamination. A recert evi :w by Dehaut et al. (2019) ${ }^{134}$ showed that the operator, the working environment, and the tec.... ${ }^{\prime} \mathrm{Ca}^{\prime}$. solutions used can be non-negligible sources of MP contamination ${ }^{134}$. For the prevention of corta. 1nation, these authors suggested a QA/QC protocol which should be applied to marine sediment. ' $\mathrm{V}$ ? noted that some studies set a clean filter next to the sample being analyzed, and then reporter the nresence or absence of MP fibers on it ${ }^{60}$. Mu et al. $(2019)^{89}$ showed that field blank concentral' ${ }^{\prime}$ s were three times higher than laboratory blanks ${ }^{89}$. Negative blanks (extraction and cleanup ,rocedures without sediment) were also investigated and recorded 0 to 4 items per blank. A few ex cf pri ons of high blank values were reported by Frere et al. and Nuelle et al., with 19 and 39 items pe bla.k, respectively ${ }^{57,96}$. The quantity of fibers detected in blanks depended on protocol duration, la vratory conditions, solvents and technical solutions used, and according to these studies, can ia subtracted from MP concentration in real samples. Solvents and solutions used also represe- ${ }^{+} \mathrm{a} \cdot \mathrm{im}_{\text {p }}$ ortant source of MPs, as shown by Vermeiren and co-authors ${ }^{109}$, who reported 0, 1, 5 and 129 MPs 1 , $200 \mathrm{~mL}$ of Nile Red solution, tap water, $\mathrm{ZnCl}_{2}$ solution and deionized water, respectively. We thus recommend the filtration of solutions before use in order to avoid contamination.

Another QA/QC step consists in artificially adding MPs to sediment before applying the complete protocol. The final quantity of spiked MP enables to evaluate the procedure recovery. A third of the 70 studies reported implementing a spiking procedure using different MP types, PE, PP, PVC and PET, shape, size and color. However, recovery depended not only on MP density, but also on color and size. Using two MP types of $3 \mathrm{~mm}$ size for sample spiking, Tsang et al. recovered $100 \%$ of spiked PP, but only $3.3 \%( \pm 5.8 \%)$ for PVC $^{106}$. Vermeiren et al. recovered more than $90 \%$ of low-density MPs (PE, PP), while dense MP (PVC, PET) recoveries were around 82-86\% (MP size added range 0.30 to $\left.0.43 \mathrm{~mm}^{2}\right)^{109}$. Recovery rates also depend on sediment particle size and concentration added (MP items per mass of sediment). For example, when testing six MP types (PE, PP, PVC, PET, PS and Nylon), Maes et al. 
shown to influence the recovery rate. For example, for PE of different colors with a size range of 0.1-1 $\mathrm{mm}$, Stolte et al. (2015) reported high recovery rates for blue, purple and green MPs (60-100\%), while recovery of yellow, orange and pink particles ranged from 0 to $40 \%{ }^{103}$. This also demonstrates that operators can introduce bias. MP spiking levels are sometime not consistent with the MP concentrations found in the field. However, spiking is an important step which permits to evaluate recovery in the overall processing protocol.

\section{III.2.6. Recommendations for MP extraction}

MP extraction is an essential step in the study of MPs in sediment. This procedure not only isolates MPs from the sediment matrix, but also helps in the identification process. Given the complexity of this procedure, we suggest that some steps must be performed priv: to MP extraction. According to

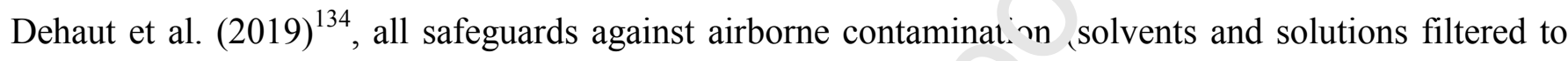
pore size $0.45 \mu \mathrm{m}$, instruments rinsed three times with clea w: ter, cotton lab coats, gloves, blank procedures in the field and laboratory) must be strictly $\mathrm{r} \mathrm{s}_{\mathrm{r}} \mathrm{ec}$ :ed at all times during analysis. Before analysis, sediment homogenization is recommended using $a \_$an spoon. The sample can then be divided into equal parts. One aliquot use for MP analysi ond another devoted for determining sediment characteristics (water, organic matter content, fmc ${ }^{\prime}$ 'n size, and other contaminants). In this case, wet sediment is preferred in order to avoid MP dey. ' for evaluating MP contamination at differe.+ size fractions. However, it does not seem well suited for fibers, as their retention is dependent upo $t^{\prime} \epsilon_{i}$ orientation during sieving. We therefore recommend that a single $5 \mathrm{~mm}$ mesh size sieve be empl 'yeci during the elimination of large items.

Separation can be performea hoth before and after the digestion step. The volume of reactant required will influence the costs of analysis. Solutions for density separation should be chosen in agreement with environme $\mathrm{ta}_{1}, \mathrm{sa}^{+}$ety, and cost considerations. Laboratories equipped with fume hoods and adequate treatment method for reagents, and lacking financial constraints, will prefer the use of $\mathrm{NaI}$ or $\mathrm{ZnCl}_{2}$ to ensure the recovery of most polymers found in the environment (PE, PS, PET, PVC), while less well-equipped laboratories will prefer $\mathrm{NaCl}$ to recover principally $\mathrm{PE}$ and $\mathrm{PS}$. We therefore recommend the addition of a 2:1 volume of solution to sediment mass repeated at least three times, and the retrieval of the supernatant using an overflow technique, involving the very gradual addition of extra solution until overflow occurs, followed by a thorough rinsing of the walls of the recipients three times with clean water. The literature demonstrates the necessity of a digestion step for sediment treatment, for which we recommend the use of $\mathrm{H}_{2} \mathrm{O}_{2} 30 \%(\mathrm{~m} / \mathrm{v})$. The added volume is determined by the NOM content of the sediment, so this addition should be realized gradually, milliliter by milliliter, until effervescence ceases. The sample can be heated to enhance the digestion step, but the temperature should not exceed 50 ${ }^{\circ} \mathrm{C}$ to avoid MP degradation. A filtration step is also recommended to increase MP recovery. The choice 


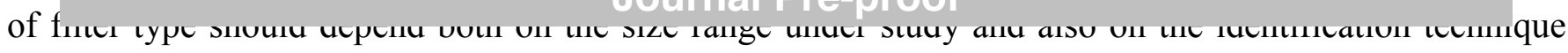
chosen for the following step.

\section{III.3. Identification techniques and results reported}

Materials and MP identification techniques in sediment are presented in Figure 3 (see Table 4 for details).

A

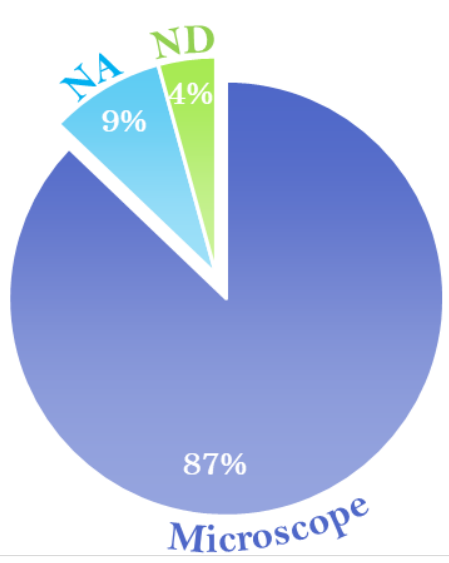

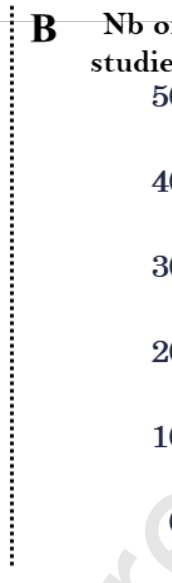

Figure 3: Techniques used for (A) visual sortı $?$ (NA=Microscope not applied, ND=technique not determined) and identification ( $\left.\iota^{\prime}\right)$ of MPs in sediments, based on 70 studies.

\section{III.3.1. Identification techniques}

Ideally, all items suspected th be MPs need to be analyzed to verify their nature. This can be performed directly after visual arting or on a filter surface. The four techniques used for MP identification in marine se ${ }^{\mathrm{i} i m}$ ?nts include visual identification, Raman, FTIR microscopy and thermal analysis; all present advantages shortcomings, and limitations, which are discussed below.

a. Visual identification

Visual identification has frequently been used for MP identification because of the tradeoff between costs and efficiency. Particles can be observed and classified based on their physical characteristics using high stereoscopic or microscopic magnification (ca. 20\% ( $\mathrm{n}=13$ ) of studies). However, this technique cannot provide chemical and/or polymer composition and also involves a high risk of under or overestimation, which depends strongly on the operator ${ }^{59}$. Hence, it shouldn't be actuated under any circumstances. The size limit for this technique depends on filter cutoff and apparatus capacity. According to two recent reviews, $100 \mu \mathrm{m}$ is the lower size limit for visual identification ${ }^{50,135}$. Scanning Electron Microscopy (SEM) can be classified as visual identification, allowing observation of particle surfaces at high resolution. This was applied in the study by Retama et al. and items were considered to be plastic when the carbon percentage measured between 60 and 72\% (using energy dispersive X-ray 


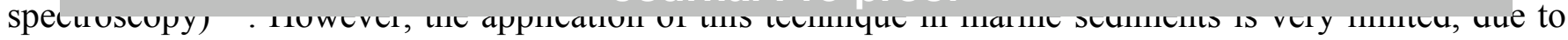
the expense and the high level of preparation required ${ }^{136}$.

b. Raman spectroscopy

Raman spectroscopy is a scattering method using a laser source, often set at 532, 632 or $785 \mathrm{~nm}$, which provides data about active vibrational chemical bonds which can be a fingerprint of the material/compound. Different spectral ranges can be used for MP identification (illustrated in Figure 4). The main advantage of this technique is that it is non-destructive, permitting non-contact analysis on samples of small mass ${ }^{136}$. It allows high size resolution (down to the $\mu \mathrm{m}$ ), and is thus useful for small MPs. Raman spectroscopy is, however, 10 to 100 times more time consuming than FTIR spectroscopy ${ }^{137}$, with an analysis time depending on the selection of measurement parameters (ranging from a few seconds to several minutes per measurement). This shortcoming is exacerl ${ }^{+}+e d$ by the very small microscope aperture, which induces high sample volume for MP extrac.10. Another drawback of Raman spectroscopy is potential by fluorescent artifacts coming from ot ${ }^{1}{ }^{-1} \mathbf{c}$ romponents, such as biological items, organic or inorganic compounds in the sample ${ }^{138}$. Cost is sotıur consideration in the use of Raman spectroscopy, due to the expensive instrument required. P ama l micro-spectroscopy ( $\mu$ Raman) has been recommended strongly for the smallest MP size fraction $(<2 \iota \mu \mathrm{m})$, which is not covered by the FTIR technique. Recently, some non-conventional tec'1s: $1 \mathrm{w} / \mathrm{s}$ and automated identification for Raman spectroscopy have been presented and may be $r_{i} g$ ow..1g interest in the future ${ }^{135,136,138}$.

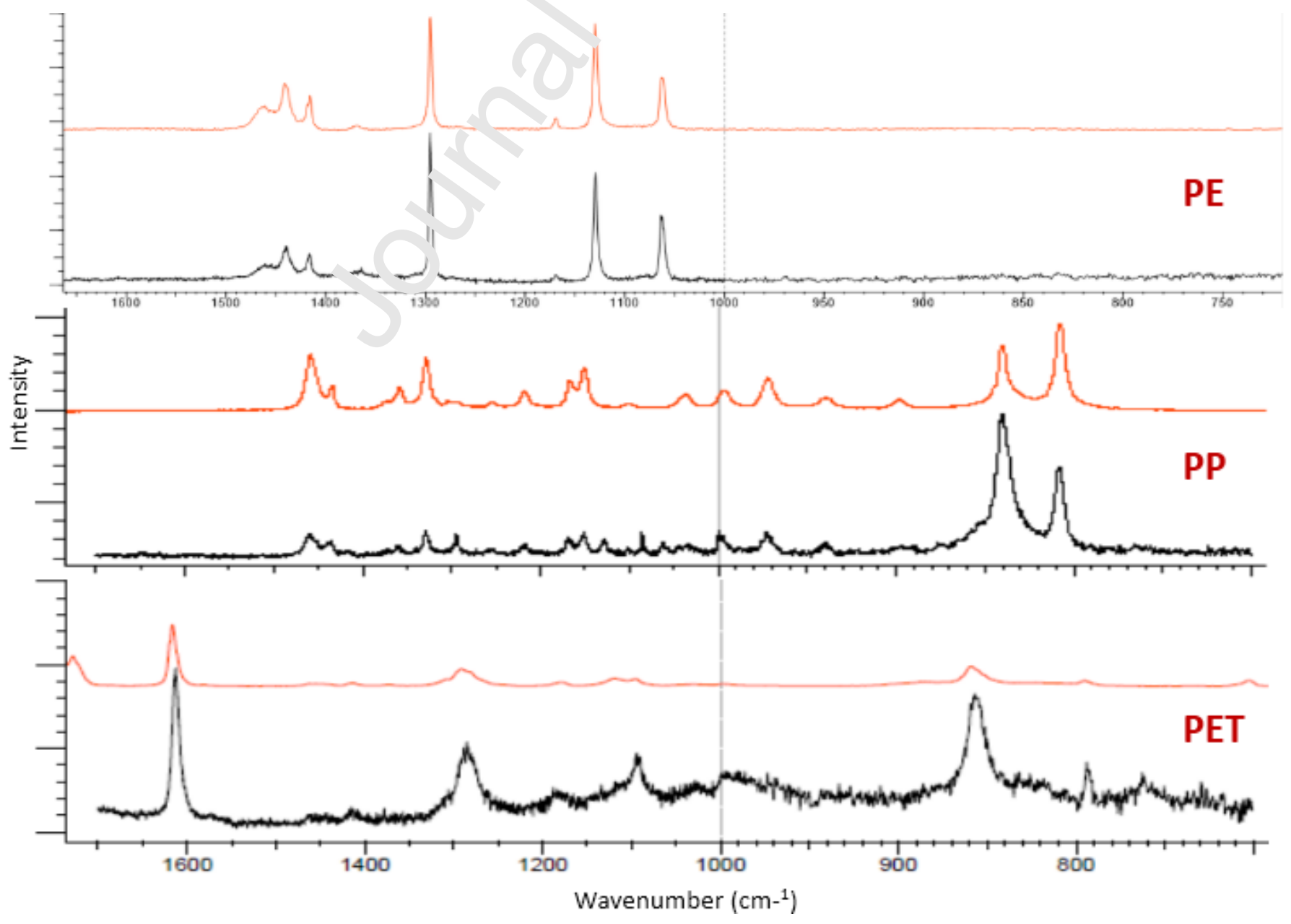




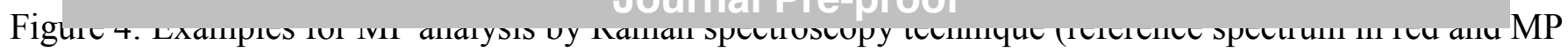
in black, measurement performed by HORIBA scientific using the laser power at $632.8 \mathrm{~nm}$ and treatment by KnowItALL ${ }^{\circledR}$ software; unpublished data). 

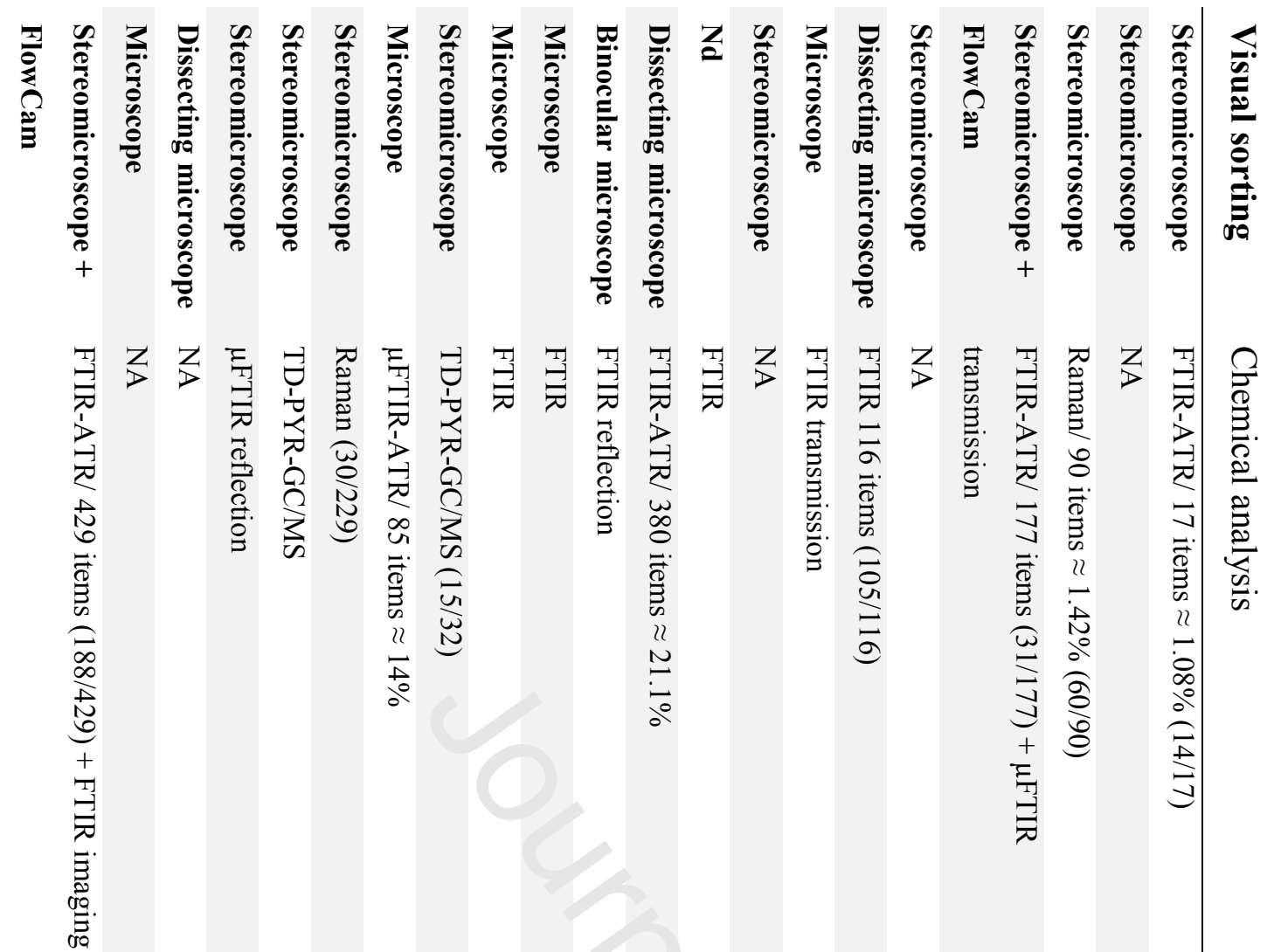

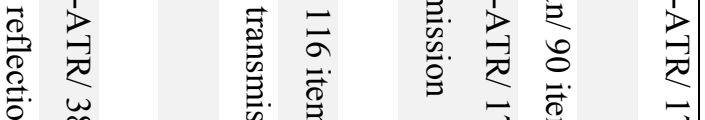

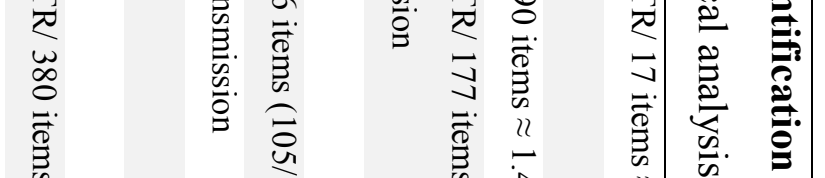

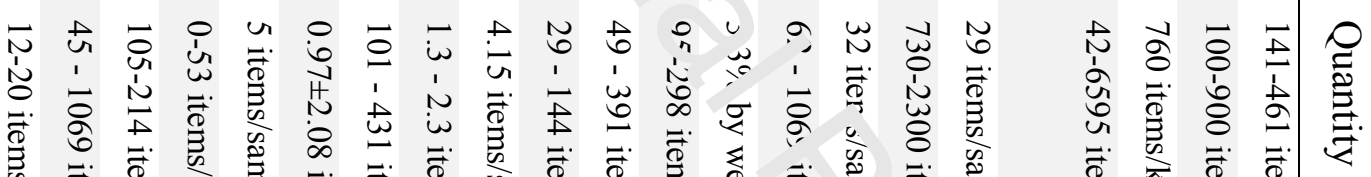

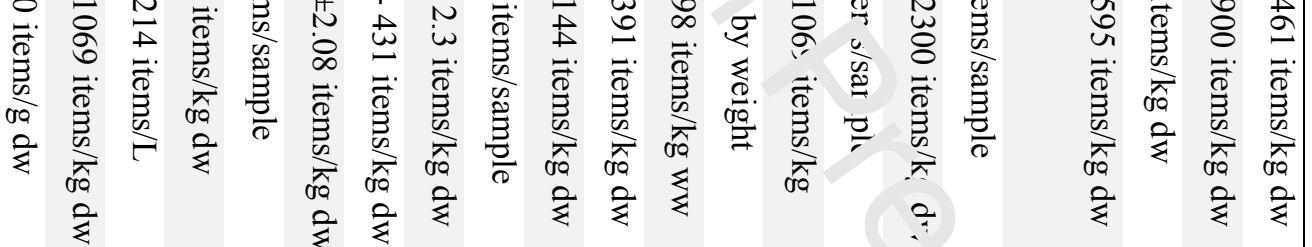
$\stackrel{2}{21}$

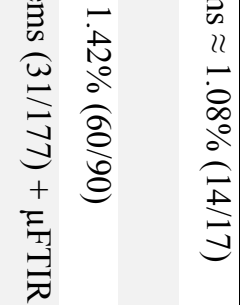

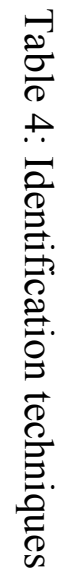

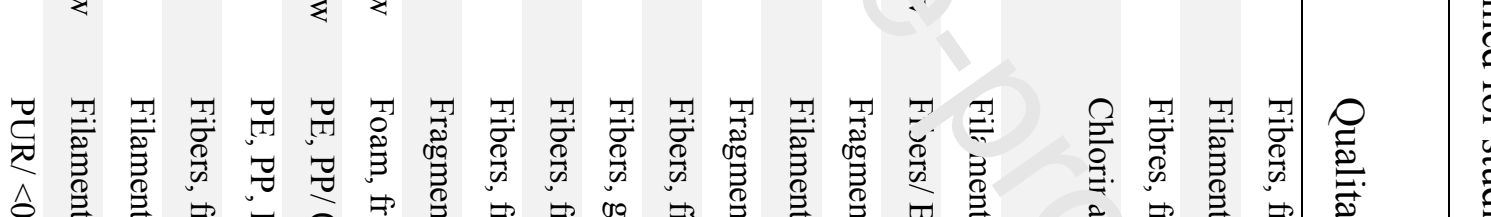

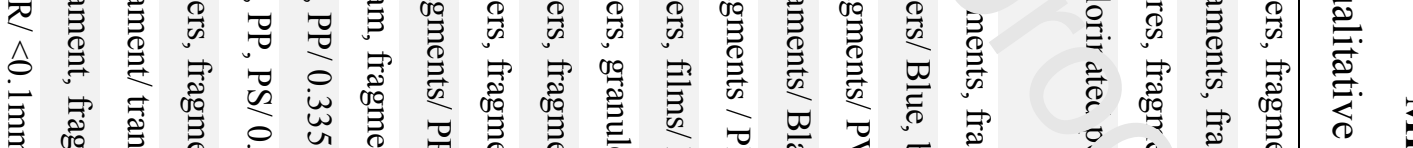

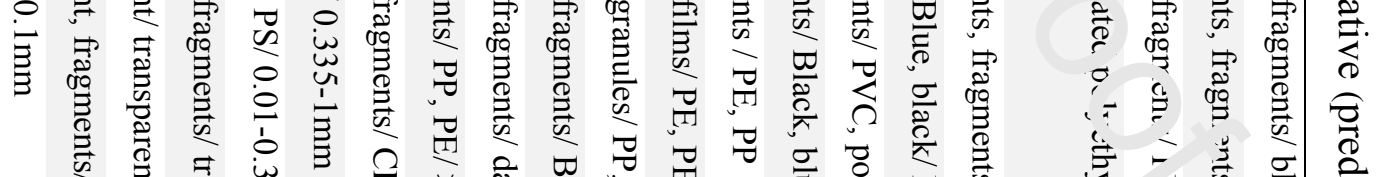

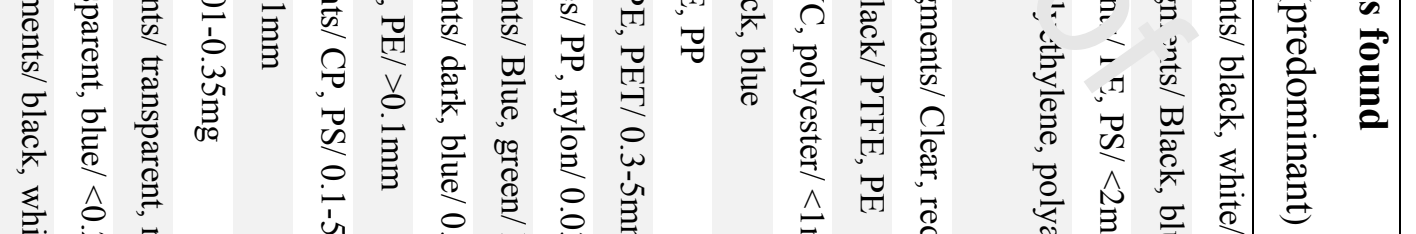

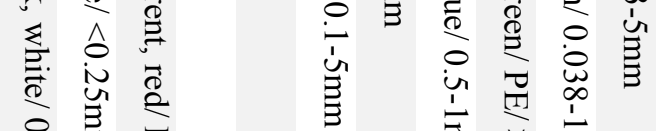

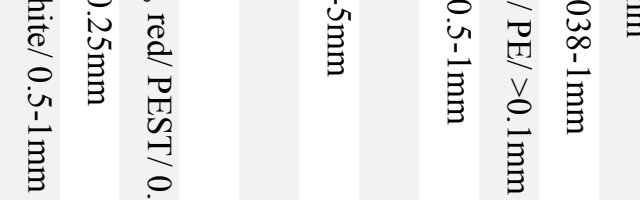

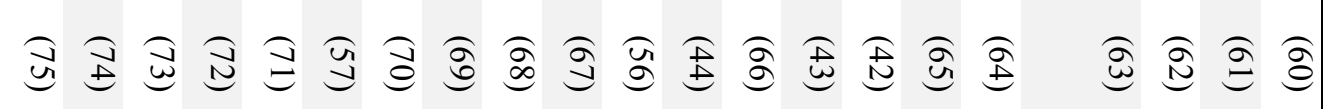



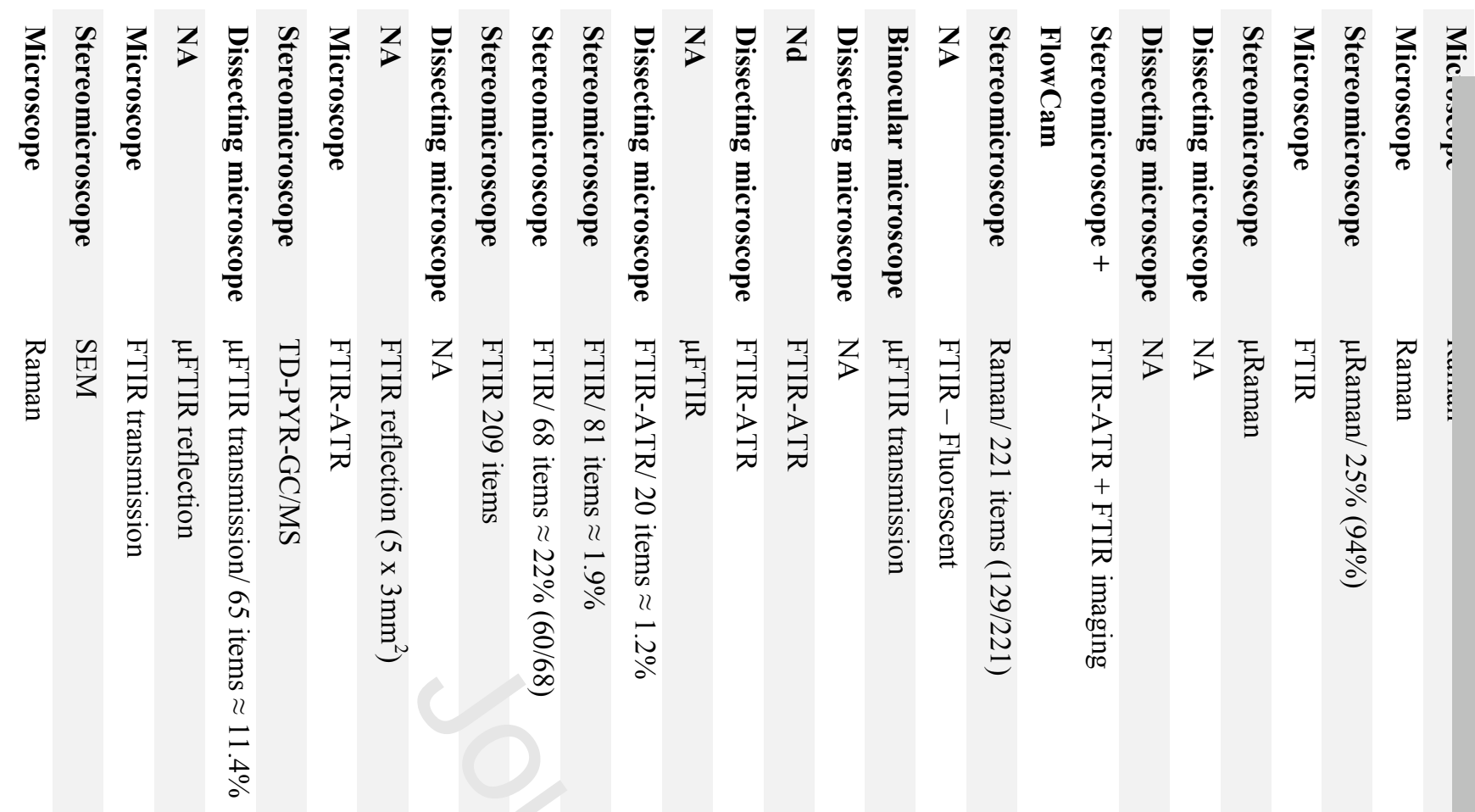

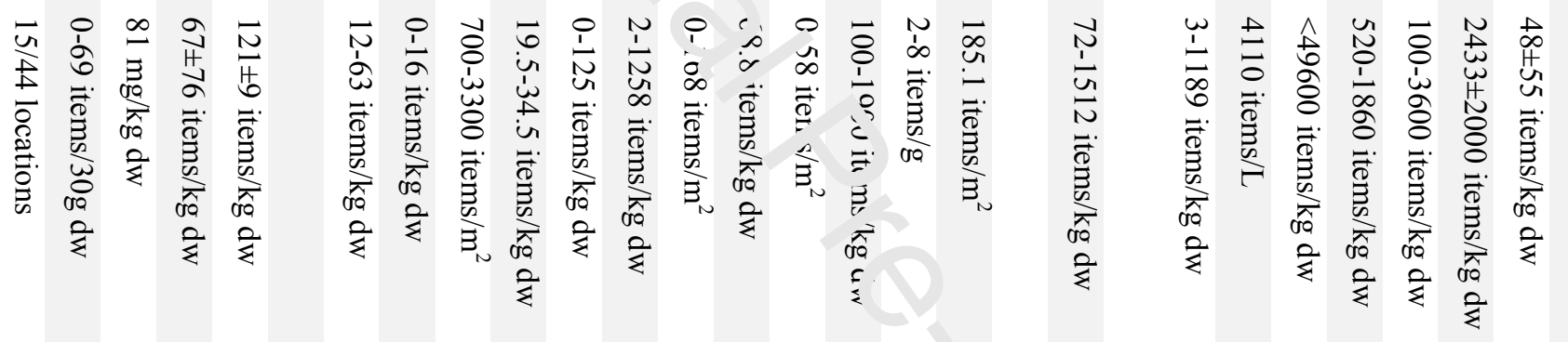

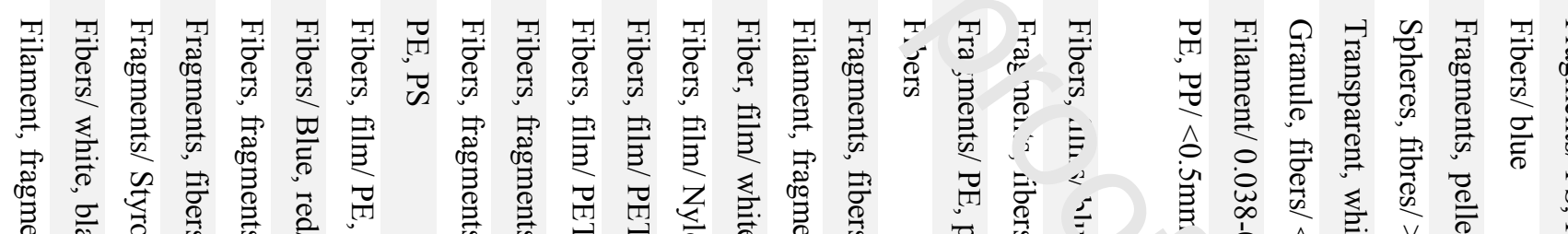

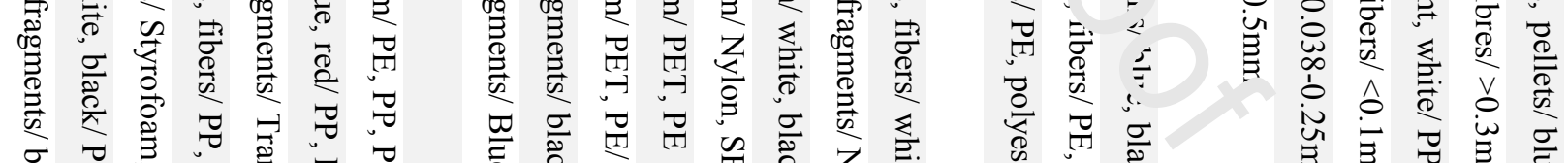

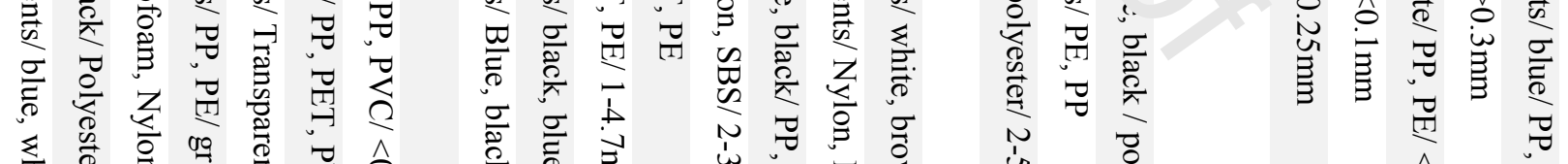

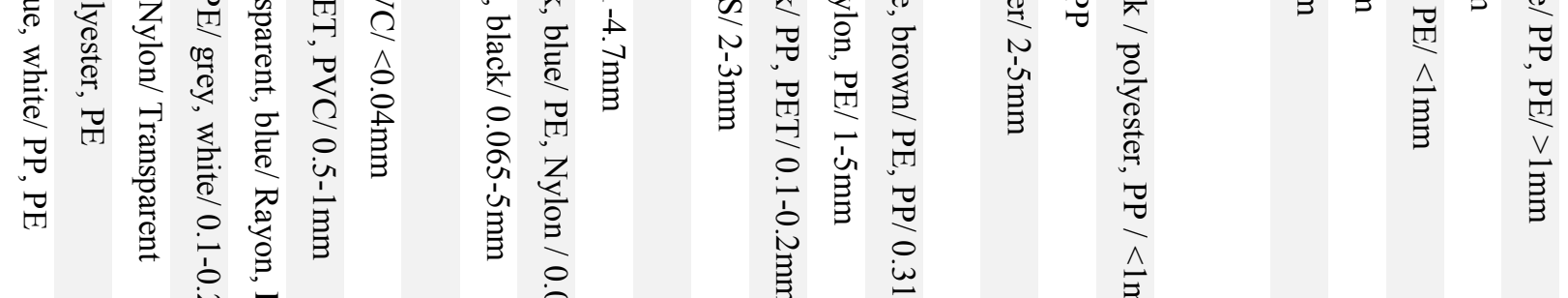
量量

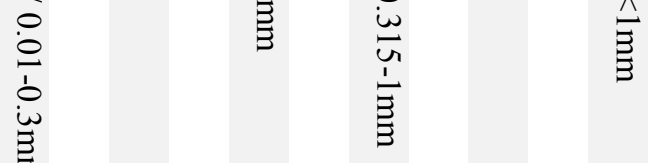

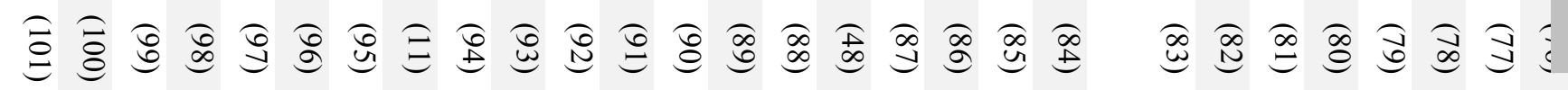



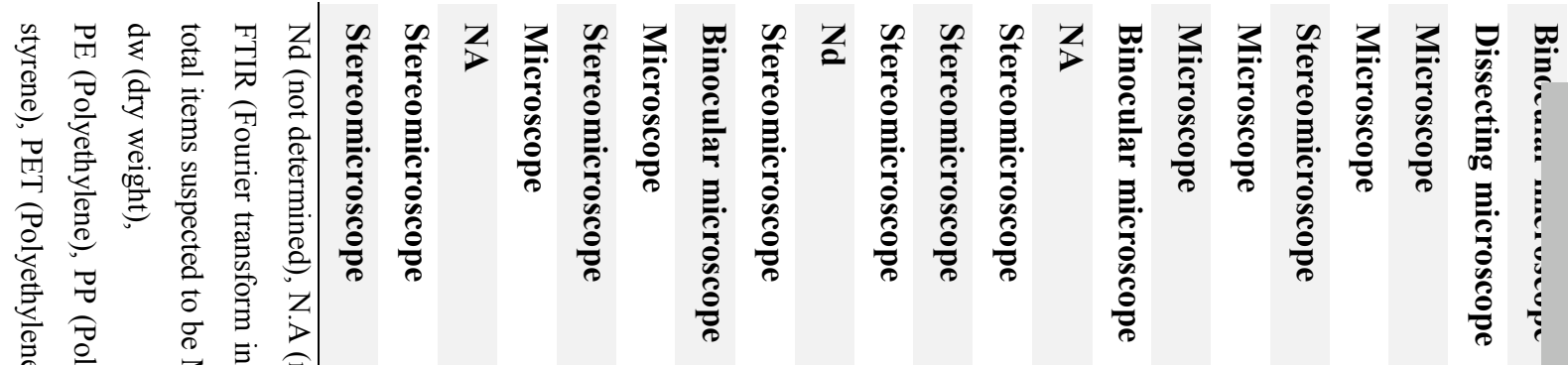

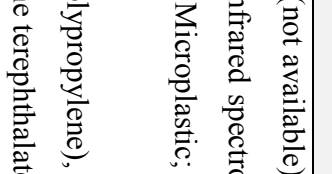

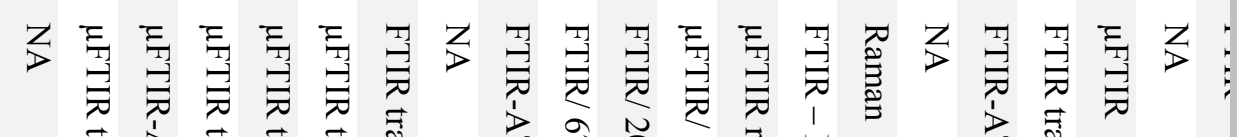

एक

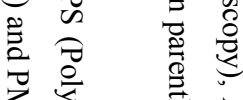

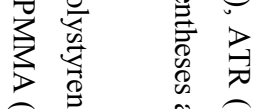

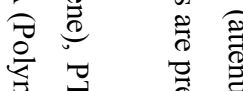

青

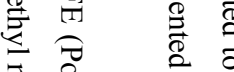

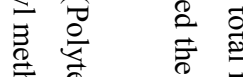

产

劳

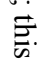

है

은

$\frac{\tilde{\sigma}}{9}$

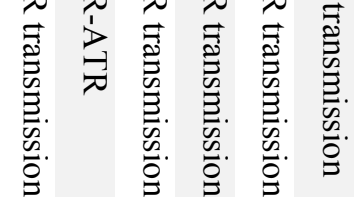

울

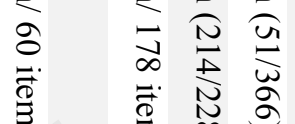

党

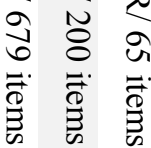

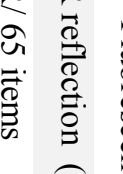

w

坣

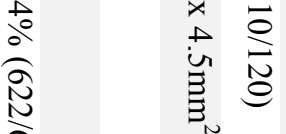

is $\frac{11}{a}$

in

बे

के

$\stackrel{2}{5}$

un

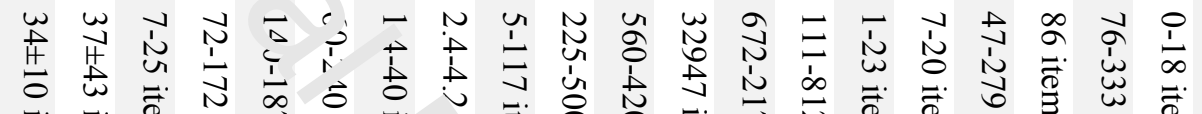

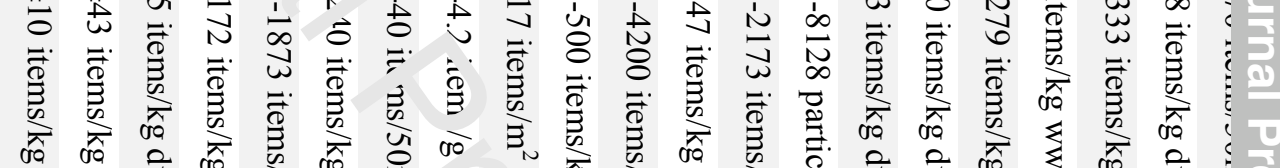

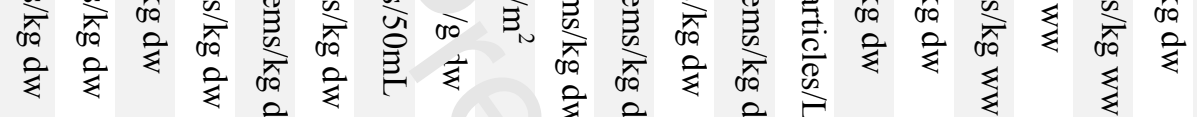

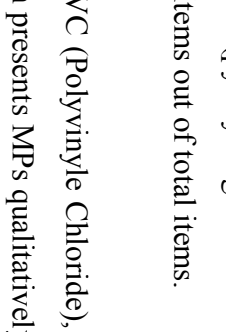

劳.

党

क

药

$\overrightarrow{0}$
8
8
8
8

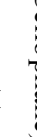

䓠

응

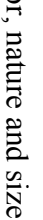

矛

일

률

㗹

8

官

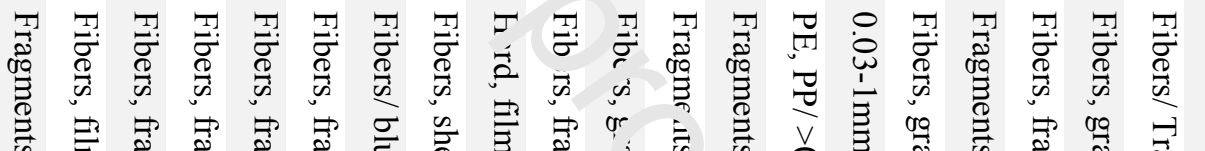

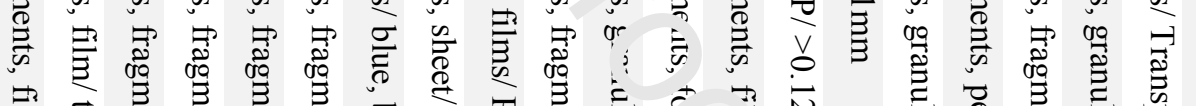

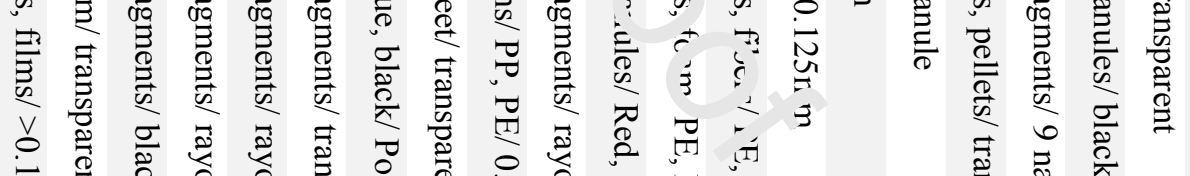

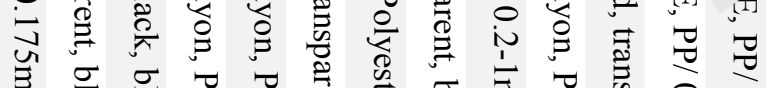

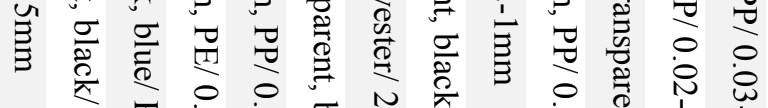

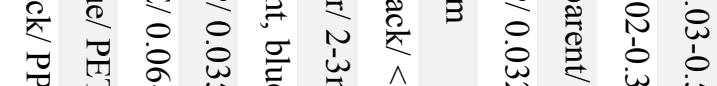

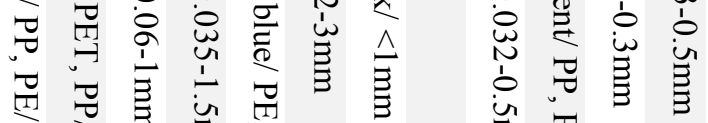

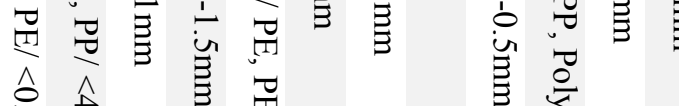

余苦

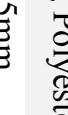

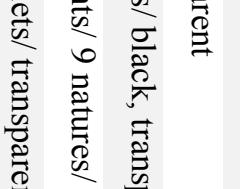

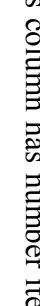

容
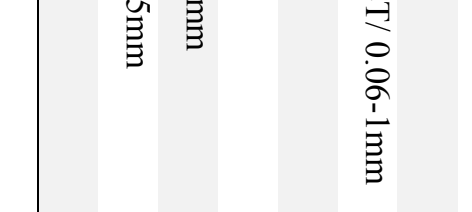

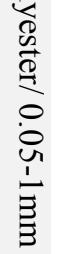

$\stackrel{\varrho}{\rightleftarrows} \stackrel{0}{\mathscr{D}}$

这范

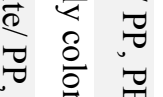

$7 \begin{array}{cc}7 & 0 \\ 0 & 0\end{array}$

- 10 
FTIR spectroscopy, like Raman, is a non-destructive technique. It is automated and is based on the two principles of reflectance and transmission with a short analysis time. FTIR is quite easy to maintain and is therefore the technique of choice for the study of MPs, and indeed represented $77 \%$ of all techniques used (five times more than Raman spectroscopy). It is a vibrational technique with an IR source which produces information on IR absorption that is connected to the nature of chemical bonds such as $\mathrm{C}-\mathrm{H}, \mathrm{C}=\mathrm{H}$ and $\mathrm{C}=\mathrm{O}$ are very easily detected by FTIR ${ }^{137}$ It has three working modes, and is thus more selective than Raman spectroscopy. When compared to Raman spectroscopy, FTIR provides strong intensities on some chemical groups such as $-\mathrm{OH}$ and $\mathrm{C}=\mathrm{O}$, which is of importance for MP degradation studies (e.g. photo-, bio-oxidation) ${ }^{138}$. However, the resolution size drops to only $10-20 \mu \mathrm{m}$ in the FTIR technique. As was seen for Raman spectroscopy, expensive ins " Tmentation is a limitation of this technique (especially for $\mu$ FTIR). An IR beam passes through th $<\mu$ rticle being measured, the signal obtained after total penetration of the particle and filter (named un uransmission mode) is reflected onto the particle's surface in the reflectance mode. The trar mısion working mode provides better information than which other one. However, transmissin $\mathrm{n}$ ode selected the filter composition and problematic on the thickness of particle. In reflectance. th $\_$A 1 R-FTIR working mode is in direct contact with the particle (on the interface of the crysta ${ }^{1}$ ), wrich possibly eliminates the influence of the environment. However, contact-analysis is one drc wback of this mode, because the crystal interface may affect another particle when measured directly o, the filter. On the other hand, single measurements are possible but require the sorting of particles $\left(h_{1}{ }_{1}{ }^{1}\right.$ picking in general, with limitations of particle size).

FTIR-imaging has been widely י י 1 .nd large databases are now available ${ }^{135}$. An MCT detector (mercury cadmium telluride) was use $1_{1}$ early study ${ }^{110}$, despite being size limited (150-200 $\mu \mathrm{m}$ ) and very time consuming ${ }^{136}$. An FPA detec 'r (Focal Plane Array) was then developed for MP studies in the environment $^{133}$. Size constrain ${ }^{+}{ }^{\circ} \mathrm{n} r$ ine FPA detector are as small as $11 \mu \mathrm{m}$, but the method is still time consuming and generates ve , lange amounts of data ${ }^{83}$. For example, Bergmann et al. analyzed $166 \mathrm{~mm}^{2}$ of filter area, and obtainea esults with 1.36 million spectra over a period of 13 hours ${ }^{63}$. Other shortcomings of FTIR-imaging are the requirements for a high purification step and the expense of the instrument (which exceeds that of the $\mu$ FTIR system).

d. Thermal analysis

Thermal analysis consists of the pyrolysis of particles at high temperature without oxygen, followed by GC-MS detection of the products, which can provide the peaks specific to the polymer composition. Such techniques were used in 3 studies on MP measurements in marine sediment, and enable the simultaneous detection of organic plastic additives (OPAs) such as phthalates (DEHP, DBP, DEP, DIBP and DMP) ${ }^{69,71,96}$, which cannot be detected using vibrational techniques (Raman and FTIR). The comparison of pyrogram between MP standard and particles sampled permit to identify the particle composition and plastic additives in a single measurement ${ }^{71}$. For example, Fries et al. $(2013)^{71}$ identified 
found randomly distributed in MP analyzed ${ }^{69,71}$. However, there are certain limitations to the application of this technique. For example, the destructive aspect of the method and the lack of information related to MP size and counting. Furthermore, this method is better adapted to single selected particle analysis (a few $\mu \mathrm{g}$ in the mass), and remains time consuming when samples are analyzed thoroughly. For example, an item analyzed by Raman or FTIR requires a few seconds to a few minutes (depending on acquisition parameters), while a pyrogram requires around 30 minutes. The limited application range in terms of size ( $>100 \mu \mathrm{m}$, operator dependent) is an additional drawback of this technique. Given the high level of attention currently paid to plastic additives, thermal analysis remains the ideal technique to complement FTIR or Raman spectroscopy.

\section{III.3.2. Results reported}

a. Quantitative results

Depending on the sampling technique and the sample pr, nar tion step chosen, MP concentrations in sediment are often expressed as items per mass $(\mathrm{g}, \mathrm{kg})$, sufface $\left(\mathrm{m}^{2}\right)$ or per volume $(\mathrm{mL}, \mathrm{L})$. They are convertible if enough sample information is available. $f_{i}$. hly variable results have been reported so far, ranging from 0 to $50.000 \mathrm{MPs}$ per $\mathrm{kg}$ of sediment $\mathrm{d} \mathrm{y}$ weight), 30 to $8.000 \mathrm{MPs}$ per $\mathrm{L}$, and 0 to 3.300 MPs per $\mathrm{m}^{2}$. This variation results from the m.1+itu ${ }^{\mathrm{l} e}$ of locations studied as well as from the different protocols and identification techniques used. '1:- nighest quantities were reported on German beaches in terms of mass concentration (East Frisia. Island, North Sea), on the Japanese coast for volume concentration and on the South Africa $i_{\text {ist }}$ as far as surface concentration is concerned ${ }^{81,94,109}$. Conversely, the lowest values were for nd 1.: the Southern Baltic Sea (MPs by mass), in the Southwestern Indian Ocean (MPs by sediment volu ne) and in the Adriatic Sea (MPs by sediment surface) ${ }^{72,88,114}$. The highest values were found in beac: a d coastal sediments while the lowest values were reported in open ocean sediments.

b. Qualitative results

Qualitative results play an important role in MP studies as the crucial information they reveal can provide hints as to potential sources. The four characteristics most used for MP reports are: nature (polymer chemical composition and density), form, size and color. To establish MP nature, a particle is considered to be made of plastic when its chemical composition corresponds to a referenced plastic material. The literature indicates that the major MPs found in sediments comprise four polymer types, including PE (toys, milk bottles), PP (bags), PS (food packaging) and PET (water bottles). This is consistent with available figures for worldwide production and utilization ${ }^{3}$. While MP nature is consistent between studies (that is not influenced by protocols or operators), other characteristics of MPs (size, form, and color) are highly study-dependent. Nevertheless, size, color and shape are useful as descriptive parameters recommended by the European MSFD technical subgroup on Marine Litter ${ }^{140}$. MP size can be determined from image analyses or directly taken from microscopic observation. Previous studies have 
ranges detected, yet it is noteworthy that although some MP studies include plastic items inferior to $1 \mathrm{~mm}$ in size, $<5 \mathrm{~mm}$ is the most widely accepted size range in other studies ${ }^{42,56}$. Indeed, agreement on a lower size limit for MPs has failed to reach a consensus, mainly due to the specificities of the different protocols applied. For example, by sieving at $38 \mu \mathrm{m}$, Claessens et al. reported a single MP size range of 0.038 to 1 $\mathrm{mm}^{56}$. Other studies endorsed sizes of MP $>100 \mu \mathrm{m}$ using hand picking and $>300 \mu \mathrm{m}$ for sieving ${ }^{70-71}$. MP size class is also divided into sub-classes in agreement with i) sieve pore size: $<63 \mu \mathrm{m}$; $63 \mu \mathrm{m}$ to $1 \mathrm{~mm}$; 1.1 to $2 \mathrm{~mm} ; 2.1$ to $4 \mathrm{~mm}$ and 4.1 to $5 \mathrm{~mm}$, ii) the identification procedure: 11 to $25 \mu \mathrm{m} ;<150 \mu \mathrm{m} ;<500$ $\mu \mathrm{m}$ and $>500 \mu \mathrm{m}$, or iii) the results obtained: 20 to $50 \mu \mathrm{m}, 51$ to $100 \mu \mathrm{m}$ and $>100 \mu \mathrm{m}^{63,64,98}$. As far as MP shape categories are concerned, the three most reported categories are fibers, filaments and fragments. MP shape can be observed and recorded with the naked $e_{j} \bullet$ or with a microscope. Other forms are listed in Table 4, and include granules, foams, films, pellets, s.1a pneres, all of which may provide consistent information as to MP sources. Most contaminatir, 1 ccurring during sample processing originates from fibers, due to their omnipresence in both out $>01$ and indoor atmospheres. Some studies therefore excluded fibers from their reports ${ }^{42,66}$. Fibers are $\cdot$ lso lifficult to identify when they are too fine. For these reasons we highly recommend the shape rankins propused by Galgani et al. ${ }^{140}$.

Regarding MP color, 12 different categories ar, proposed by Galgani et al ${ }^{140}$. MP color is recorded by direct observation by the operatc. $\mathrm{o}$ the experiment. According to several of the studies, many colors were reported for MPs found in narine sediments, including black, white, red, blue, transparent and brown. The designation of n $\mathrm{l}^{-}$- must, however, be treated with caution. For example, an apparently transparent MP may (i) have u n ergone long environmental weathering leading to loss of color, (ii) have lost its color during s an nle treatment (e.g., during organic matter digestion), (iii) appear transparent due to the light density a.ring measurement, or (iv) be intrinsically transparent ${ }^{65}$.

\section{III.3.3. Recommendation 'or MP identification and results report}

To date, the identificatic a of all MP extracted from marine sediment is not yet feasible due to time of analysis and/or the limitations of the techniques used. Studies reviewed here were often performed only on items suspected to be MPs (using microscopic observation). The ratio (items selected/items extracted) and identification are presented in Table 4: 25 studies treated this issue. Firstly, it could be shown that small ratio sorted (1 to $33 \%$ of total) then verified as MP via spectrum measure. This seems reasonable because many particles with different characteristics remain on the sieve/filter. For this reason, hand sorting of MPs is very time consuming or even impossible for the smallest items. Once an item is isolated, it is possible to classify it as being a MP, or to rule it out after verification using various identification techniques. The values (accepted items / total items) are presented in parentheses in the chemical analysis column of Table 4. Positively, high ratio of items selected are verified as MP among these reports which up to $92 \%{ }^{109,112}$. An automatic MP identification that would exclude these biases would be optimal for future work. 
randomly) be verified. Successful rate (items accepted/items total) will be used for whole items observed. A combination of techniques would permit to identify all items and with more consistency. This suggests that three fractions of MP size should be measured separately: large sized items $(>500 \mu \mathrm{m})$ using FTIRATR, medium sized pieces (ranging from 20 to $500 \mu \mathrm{m}$ ) via $\mu$ FTIR (reflectance or transmittance), and small size particles $(<20 \mu \mathrm{m})$ using Raman spectroscopy. Regarding instrument cost, Raman spectroscopy and $\mu$ FTIR may not be within the means of all laboratories but difficulties in accessing these instruments could be overcome by cooperation between institutions. For organic plastic additives in MP, thermal analysis is recommended. On the other hand, chemical extraction has been well developed in recent years for these compounds ${ }^{141-143}$.

Concentration report can be calculated by number of MPs on try mass, although we recommend a protocol on wet sediment but convertible with water content. Whf I I sults are calculated by volume or area, full sampling information should be provided to ensure reici inty. As the most-used means of MP identification, the categories proposed by Galgani et al. are str ng $_{1 y}$ recommended for use and reporting.

\section{Challenges of Nanoplastics}

Although studies on MP size fractions ' in $^{11} v_{c} \cdot$ y due to the various methodologies being used as presented above, the attention paid to the smalı - fraction at the nanoscale (nanoplastics, NPs, 1 to 100 $\mathrm{nm})^{144}$ has been growing since 2017. In th ${ }^{2} \mathrm{ry}$, a $50 \mu \mathrm{m}$ MP (the size most commonly found in the environment) could fragment into up to $125 \mathrm{t}$ illion NPs of $1 \mathrm{~nm}$ size, which would have a much bigger active surface area. These particles s'so rave a higher accumulation capacity and a higher toxicity, possibility due to more efficient ropic transfer and potential cell penetration. Just like MPs in the environment, NPs have two distin ' ${ }^{+}$ources. While primary NPs originate from personal care products, the secondary source com $\epsilon_{\text {fr }} m$.he fragmentation of plastic waste due to environmental conditions ${ }^{145}$. Sharing the same workflow ns MP analysis, methods used for the NP size fraction have some principal steps such as sample preparation, filtration and identification. To date, only few studies have reported the presence of NPs in seawater and snow samples and analysis is still limited to a few polymer types ${ }^{146,147}$. The sample preparation step requires a combination of multiple sub-steps in order to purify the sample. For environmental samples, a digestion step is necessary due to the presence of natural organic matter. Other non-plastic materials must be removed as good as possible. Furthermore, NP mass concentrations in the environment are often very low and therefore require a high pre-concentration rate of the sample ${ }^{144}$. Once the sample is purified, particles bigger than $1 \mu \mathrm{m}$ can be removed using a filtration technique, while the smaller fraction is used for NP analysis. Some techniques such as ultrafiltration, ultracentrifugation, evaporation of solvent or dialysis may help to concentrate the sample ${ }^{148,149}$. When studying MP size fractions, particles are identifiable by measuring the residue on the sieve or filter surface using spectroscopy. However, this method is not yet applicable for NP size fractions. Several techniques can be 


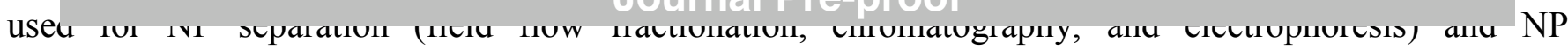

characterization (light scattering, electron microscopy) $^{149}$. The identification of NPs is more difficult, requiring a combination of analytical methods, and is therefore more expensive ${ }^{135}$. Direct identification of large NPs $(>450 \mathrm{~nm}$ ) could be achieved by using HR SEM (High Resolution SEM) combined with Raman or imaging mass spectroscopy TOF/SIMS (Time of flight secondary ion mass spectrometry) ${ }^{150,151}$. However, this approach needs to be further developed. On the other hand, a thermal analytical method coupled with mass spectrometry seems more utilizable for NP identification. Thermal treatment (Py pyrolysis or TED - thermoextraction and desorption) allows to have low molecular weight from macromolecules. These molecules are then separated and analyzed using GC-MS to identify the polymer composition $^{152}$. The recently developed Raman tweezers technique allows to identify NPs down to $50 \mathrm{~nm}$ in seawater samples ${ }^{153}$. The study of NPs in marine sediments has nc ret been reported but constitutes an important research topic for the future.

\section{Conclusion}

Different protocols are used for the evaluation of $\mathrm{M}^{\mathrm{T}}$ c n ntamination in marine sediments. It is thus difficult to compare the reported results and to draw up a $r{ }^{r}$ lia ${ }^{1}$ e protocol for future studies. With the aim of obtaining comparable results, our recommendation: a e esumed in Figure 5.

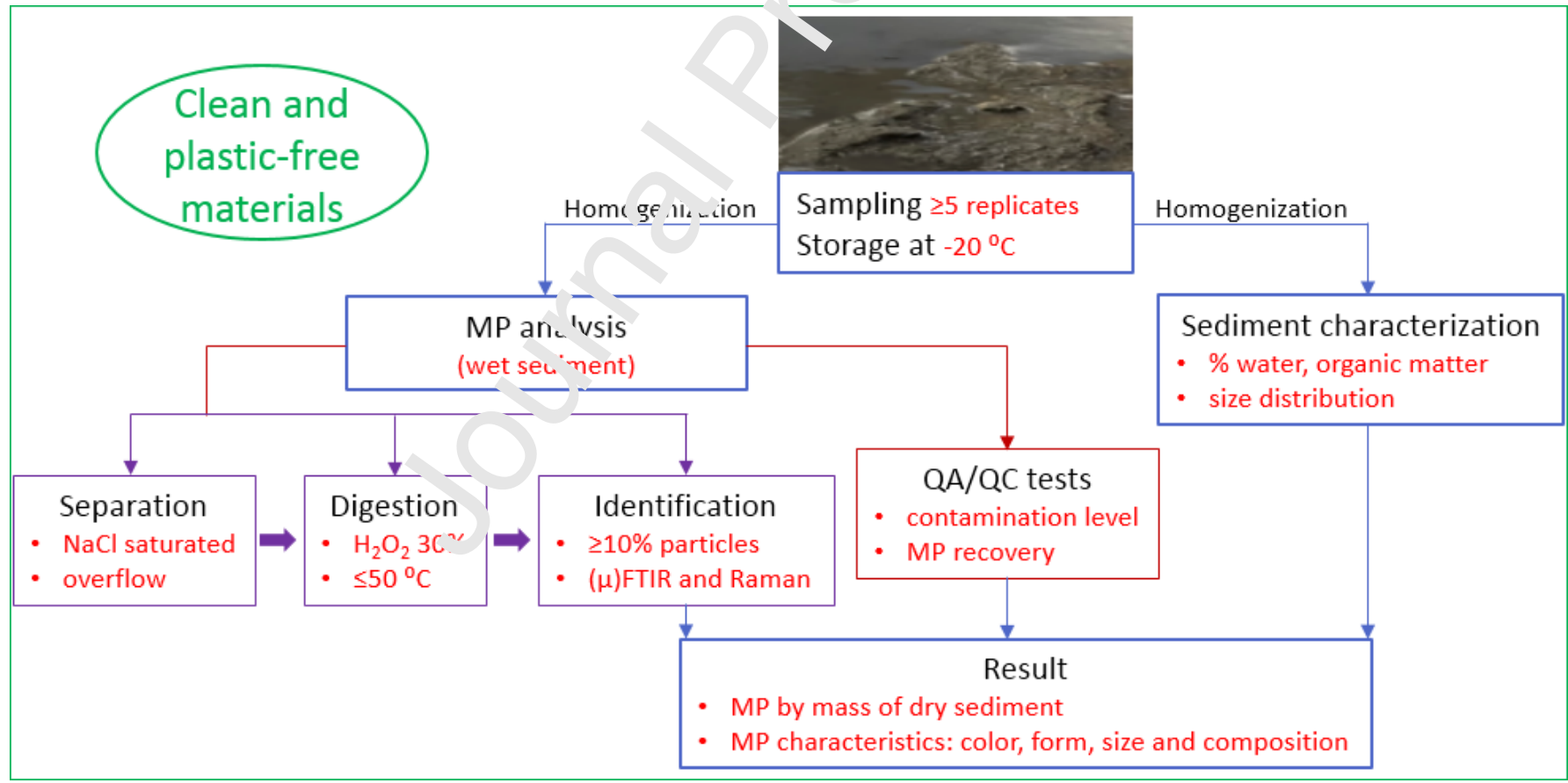

Figure 5: Recommendation for a reliable workflow of MP analysis in marine sediment

Taking into account aspects dealing with cost and ecology, we recommend the use of $\mathrm{NaCl}$ solution for the separation step. Although there are many denser solutions available for use such as $\mathrm{ZnCl}_{2}$, $\mathrm{CaCl}_{2}, \mathrm{NaI}$, each one has shortcomings, including viscosity, toxicity or expense when compared to a $\mathrm{NaCl}$ solution. A digestion step using an $\mathrm{H}_{2} \mathrm{O}_{2}$ solution should be applied for organic matter elimination. This solution is more readily available than enzymatic solutions, and has less influence on MP degradation 


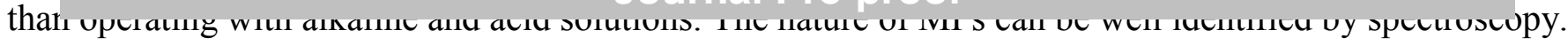
Vibrational spectroscopies (FTIR and Raman) have been shown to be the techniques of choice. We further suggest the measurement of sediment characteristics (size distribution, water and organic matter content) in parallel with those used for MP analysis. The QA/QC (blanks analysis, spiked samples, working conditions) must always be respected to prevent sample contamination, and enable the evaluation of MP recovery depending on the protocol used. The use of plastic-free apparatus during sample processing is a necessity for the prevention of a large part of sample contamination. Automatic identification (involving neither the naked eye nor microscope observation) is recommended to avoid operator bias (e.g., $\mu$ FTIR). The very recent technique of LDIR (Laser Direct Infra-Red) may also be a valuable solution but it has not been applied to marine sediments yet. Lastly, the occurrence of NPs in marine sediments is a new analytical challenge that will need to be ta $\%$ led in the coming years.

\section{Acknowledgments}

The authors would like to thank the French National Resez icn Agency (ANR) for financial support. This work is part of the TRAJECTOIRE project (2019-2023) $1_{\perp}$ anks are given to Frederique Eyrolle and other partners in this project. This study was also part v st pported by the JPI-Ocean Andromeda, Agence de l'Eau-CAREMED, Agence de l'Eau-PLAST'- SL'? projects and contributes to the CONTAM project of MIO. 


\section{References}

(1) Andrady, A.L.; Neal, M.A. Applications and societal benefits of plastics. Philos. Trans. R. Soc. Lond., B, Biol. Sci. 2009, 364, 1977-1984.

(2) PlasticsEurope, 2019. Plastics - the Facts 2019: An analysis of European plastics production, demand and waste data.

(3) Geyer, R.; Jambeck, J. R.; Law, K. L. Production, use, and fate of all plastics ever made. Sci. Adv. 2017, 3(7), e1700782.

(4) Hopewell, J.; Dvorak, R.; Kosior, E. Plastics recycling: challenges and opportunities. Philos. Trans. R. Soc. Lond., B, Biol. Sci. 2009, 364(1526), 2115-2126.

(5) Jambeck, J.R.; Geyer, R.; Wilcox, C.; Siegler, T.R.; Perryman, M.; Andrady, A., et al. Plastic waste inputs from land into the ocean. Science. 2015, 347, 768-771

(6) Arthur, C.; Baker, J.; Bamford, H., 2009. In Proceedin ss of .he International Research Workshop on the Occurrence, Effects and Fate of Microplastic Ma in Lebris, NOAA Technical Memorandum NOS-OR \& R-30.NOAA (p. 530). Silver Spring, Septemb $f_{i}$ y. 11, 2008.

(7) Van Cauwenberghe, L.; Devriese, L.; Galgar '. F. Robbens, J.; Janssen, C. R. Microplastics in sediments: a review of techniques, occurrence a a tis ts. Mar. Environ. Res. 2015, 111, 5-17.

(8) Gigault, J.; Ter Halle, A.; Baudrimont, : '.; Pascal, P. Y.; Gauffre, F.; Phi, T. L.; et al. Current opinion: What is a nanoplastic? Environ. Polı.t. 2018, 235, 1030-1034.

(9) Wagner, M.; Scherer, C.; Alvarez I lu 10z, D.; Brennholt, N.; Bourrain, X.; Buchinger, S.; et al. Microplastics in freshwater ecosysten. ' wnat we know and what we need to know. Environ. Sci. Eur. 2014, 26, 12.

(10) $\mathrm{Ng}, \mathrm{K}$ L.; Obbard, J.P. Pr ${ }_{\text {rr. }}$ ence of microplastics in Singapore's coastal marine environment. Mar. Pollut. Bull. 2006, 52, 76, -7, 7 .

(11) Mattsson, K.; Hanssnn L.-A.; Cedervall, T. Nano-plastics in the aquatic environment. Environ. Sci. Process. Impacts. 2017, 17, 1712-1721.

(12) Bessa, F., Ratcliffe, N., Otero, V., Sobral, P., Marques, J. C., Waluda, C. M., Xavier, J. C. Microplastics in gentoo penguins from the Antarctic region. Sci. Rep. 2019, 9(1), 1-7.

(13) Carr, S.A.; Liu, J.; Tesoro, A.G. Transport and fate of microplastic particles in wastewater treatment plants. Water Res. 2016, 91, 174-182.

(14) Napper, I. E.; Bakir, A.; Rowland, S. J.; Thompson, R. C. Characterisation, quantity and sorptive properties of microplastics extracted from cosmetics. Mar. Pollut. Bull. 2015, 99(1-2), 178-185.

(15) Prata, J. C. Microplastics in wastewater: State of the knowledge on sources, fate and solutions. Mar. Pollut. Bull. 2018, 129(1), 262-265.

(16) Andrady, A.L. Microplastics in the marine environment. Mar. Pollut. Bull. 2011, 62, 1596-1605 


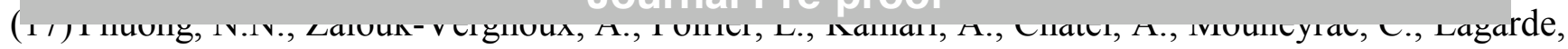

F. Is there any consistency between the microplastics found in the field and those used in laboratory experiments? Environ. Pollut. 2016, 211, 111-123.

(18) Wright, S.L.; Rowe, D.; Thompson, R.C.; Galloway, T.S. Microplastic ingestion decreases energy reserves in marine worms. Curr. Biol. 2013, 23, 1031-1033.

(19) Besseling, E.; Foekema, E.M.; Van Franeker, J.A.; Leopold, M.F.; Kühn, S.; Bravo Rebolledo, E.L.; Heße, E.; Mielke, L.; IJzerc, J.; Kamminga, P.; Koelmans, A.A. Microplastic in a macro filter feeder: Humpback whale Megaptera novaeangliae. Mar. Pollut. Bull. 2015, 95, 248-252.

(20) Cózar, A.; Sanz-Martín, M.; Martí, E.; González-Gordillo, J.I.; Ubeda, B.; Gálvez, J.Á.; Irigoien, X.; Duarte, C.M. Plastic accumulation in the Mediterranean Sea. 2015, PLOS ONE, 10(4), e0121762.

(21) Desforges, J.P.W.; Galbraith, M.; Dangerfield, N.; Ros, P.S. Widespread distribution of microplastics in subsurface seawater in the NE Pacific Ocean. Mar. ro.'uı. Bull. 2014, 79, 94-99.

(22) Desforges, J.P.W.; Galbraith, M.; Ross, P.S. Ingestion of Vucroplastics by Zooplankton in the Northeast Pacific Ocean. Arch. Environ. Contam. Toxicol. 201 ;, 0>, 320-330.

(23) Dris, R.; Gasperi, J.; Rocher, V.; Saad, M.; Renau ${ }^{1}$. N. Tassin, B. Microplastic contamination in a urban area: a case study in Greater Paris. Environ. Chem. 201_a, 12, 592-599.

(24) Dris, R.; Imhof, H.; Sanchez, W.; Gasperi, I., I₹ tgani, F.; Tassin, B.; Laforsch, C. Beyond the ocean: contamination of freshwater ecosyster s $v$ ith (micro-) plastic particles. Environ. Chem. 2015b, 12(5), 539-550.

(25) Fischer, E. K.; Paglialonga, L.; Czerh, : ; Tamminga, M. Microplastic pollution in lakes and lake shoreline sediments - A case study on I a e Bolsena and Lake Chiusi (Central Italy). Environ. Pollut. 2016, 213, 648-657.

(26) Free, C.M.; Jensen, O.P.; Ma`nı. S.A.; Eriksen, M.; Williamson, N.J.; Boldgiv, B. High-levels of microplastic pollution in a larg`, ' 'nıte, mountain lake. Mar. Pollut. Bull. 2014, 85, 156-163.

(27) Gasperi, J.; Dris, R.; M/luande-Bret, C.; Mandin, C.; Langlois, V.; Tassin, B. First overview of microplastics in indoor and uuddoor air. In: 15 th EuCheMS International conference on Chemistry and Environment.

(28) Huerta Lwanga, E.; Gertsen, H.; Gooren, H.; Peters, P.; Salanki, T.; Van de Ploeg, M.; Besseling, E.; Koelmans, A.A.; Geissen, V. Microplastics in the Terrestrial Ecosystem: Implications for Lumbricus terrestris (Oligochaeta, Lumbricidae). Environ. Sci. Technol. 2016, 50, 2685-2691.

(29) Karami, A.; Golieskardi, A.; Choo, C. K.; Romano, N.; Ho, Y. B.; Salamatinia, B. A highperformance protocol for extraction of microplastics in fish. Sci. Total. Environ. 2017, 578, 485-494.

(30) Phuong, N. N.; Poirier, L.; Pham, Q. T.; Lagarde, F.; Zalouk-Vergnoux, A. Factors influencing the microplastic contamination of bivalves from the French Atlantic coast: Location, season and/or mode of life? Mar. Pollut. Bull. 2018b, 129, 664-674. 


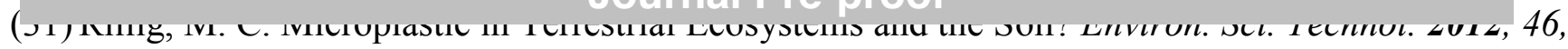
6453-6454.

(32) Revel, M.; Châtel, A.; Perrein-Ettajani, H.; et al. Realistic environmental exposure to microplastics does not induce biological effects in the Pacific oyster Crassostrea gigas. Mar. Pollut. Bull. 2020, 150, 110627.

(33) Bakir, A.; Rowland, S.J.; Thompson, R.C. Enhanced desorption of persistent organic pollutants from microplastics under simulated physiological conditions. Environ. Pollut. 2014, 185, 16-23.

(34) Julienne, F.; Delorme, N.; Lagarde, F. From macroplastics to microplastics: Role of water in the fragmentation of polyethylene. Chemosphere, 2019, 236, 124409.

(35) Eriksen, M.; Maximenko, N.; Thiel, M. Plastic pollution in the South Pacific subtropical gyre. Mar. Pollut. Bull. 2013, 68, 71-76.

(36) Eriksen, M.; Lebreton, L.C.M.; Carson, H.S.; Thiel, M.; Mc ure, C.J.; et al. Plastic Pollution in the World's Oceans: More than 5 Trillion Plastic Pieces Weighing uvr 250,000 Tons Afloat at Sea. 2014, PLOS ONE 9(12): e111913.

(37) Floren, H. P.; Shugart, G. W. Plastic in Cassin's Av lets (Ptychoramphus aleuticus) from the 2014 stranding on the Northeast Pacific Coast. Mar. Pollut. Bul.. 201 7, 117(1-2), 496-498.

(38) Jabeen, K.; Su, L.; Li, J.; Yang, D.; Tong, C., V', J.; Shi, H. Microplastics and mesoplastics in fish from coastal and fresh waters of China. En irc 2. F Jllut. 2017, 221, 141-149.

(39) Pham, C. K.; Rodríguez, Y.; Dauphin, s · Carriço, R.; Frias, J. P.; Vandeperre.; et al. Plastic ingestion in oceanic-stage loggerhead sea tritlc. (Caretta caretta) off the North Atlantic subtropical gyre. Mar. Pollut. Bull. 2017, 121(1-2), 222-279.

(40) Steer, M.; Cole, M.; Thompsc n, ?. C.; Lindeque, P. K. Microplastic ingestion in fish larvae in the western English Channel. Environ. I vlıut. 2017, 226, 250-259.

(41) Laglbauer, B.J.L.; Fra w-Santos, R.M.; Andreu-Cazenave, M.; Brunelli, L.; Papadatou, M.;

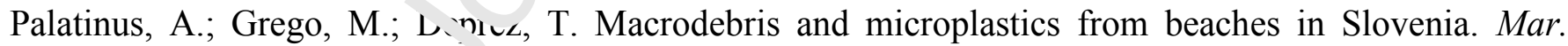
Pollut. Bull. 2014, 89, 356-3vú.

(42) Browne, M.A.; Galloway, T.S.; Thompson, R.C. Spatial patterns of plastic debris along estuarine shorelines. Environ. Sci. Technol. 2010, 44, 3404-3409.

(43) Cannas, S.; Fastelli, P.; Guerranti, C.; Renzi, M. Plastic litter in sediments from the coasts of south Tuscany (Tyrrhenian Sea). Mar. Pollut. Bull. 2017, 119, 372-375.

(44) Cheang, C. C.; Ma, Y.; Fok, L. Occurrence and composition of microplastics in the seabed sediments of the coral communities in proximity of a metropolitan area. Int. J. Environ. Res. Public Health. 2018, 15(10), 2270.

(45) Karlsson, T. M., Hassellöv, M., Jakubowicz, I. Influence of thermooxidative degradation on the in situ fate of polyethylene in temperate coastal waters. Mar. Pollut. Bull. 2018, 135, 187-194. 


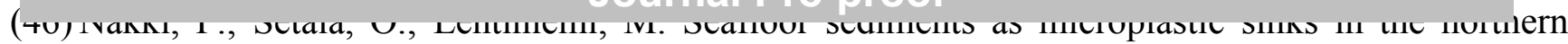

Baltic Sea-Negligible upward transport of buried microplastics by bioturbation. Environ. Pollut. 2019, $249,74-81$.

(47) Taylor, M. L.; Gwinnett, C.; Robinson, L. F.; Woodall, L. C. Plastic microfibre ingestion by deepsea organisms. Sci. rep. 2016, 6(1), 1-9.

(48) Matsuguma, Y.; Takada, H.; Kumata, H.; Kanke, H.; Sakurai, S.; Suzuki, T.; Itoh, M.; Okazaki, Y.; Boonyatumanond, R.; Zakaria, M.P.; Weerts, S.; Newman, B. Microplastics in Sediment Cores from Asia and Africa as Indicators of Temporal Trends in Plastic Pollution. Arch. Environ. Contam. Toxicol. 2017, 1-10.

(49) Willis, K. A.; Eriksen, R.; Wilcox, C.; Hardesty, B. D. Microplastic distribution at different sediment depths in an urban estuary. Front. Mar. Sci. 2017, 4, 419.

(50) Hanvey, J.S., Lewis, P.J., Lavers, J.L., Crosbie, N.D., Pozo K., Clarke, O. A review of analytical techniques for quantifying microplastics in sediments. Anal. Met'uv 1s. 2017, 9, 1369.

(51) Prata, J. C., da Costa, J. P., Duarte, A. C., \& Ro ha-santos, T. Methods for sampling and detection of microplastics in water and sediment: a 'riti al review. Trends. Anal. Chem,2019, 110, 150-159.

(52) Yao, P., Zhou, B., Lu, Y., Yin, Y., Zong, '.. Chen, M. T., \& O'Donnell, Z. A review of microplastics in sediments: Spatial ar $\mathfrak{t}$ mpural occurrences, biological effects, and analytic methods. Quat. Int. 2019, 519, 274-281.

(53) Cashman, M. A., Ho, K. T., Boving T. R., Russo, S., Robinson, S., \& Burgess, R. M. Comparison of microplastic isolation and extra ti un procedures from marine sediments. Mar. Pollut. Bull. 2020, 159, 111507.

(54) Harris, P. T. The fate of nicroplastic in marine sedimentary environments: A review and synthesis. Mar. pollut. F, ü $^{11} \angle U 20,158,111398$.

(55) Yang, L., Zhang, Y., Kang, S., Wang, Z., \& Wu, C. Microplastics in freshwater sediment: A review on methods, ocuurrence, and sources. Sci. Total. Environ. 2020, 141948.

(56) Claessens, M.; De Meester, S.; Van Landuyt, L.; De Clerck, K.; Janssen, C.R. Occurrence and distribution of microplastics in marine sediments along the Belgian coast. Mar. Pollut. Bull. 2011, 62, 2199-2204.

(57) Frere, L.; Paul-Pont, I.; Rinnert, E.; Petton, S.; Jaffre, J.; Bihannic, I.; Soudant, P.; Lambert, C.; Huvet, A. Influence of environmental and anthropogenic factors on the composition, concentration and spatial distribution of microplastics: A case study of the Bay of Brest (Brittany, France). Environ. Pollut. 2017, 225, 211-222.

(58) Wang, Z.; Su, B.; Xu, X.; Di, D.; Huang, H.; Mei, K.; Shang, X. Preferential accumulation of small $(<300 \mu \mathrm{m})$ microplastics in the sediments of a coastal plain river network in eastern China. Water. Res. 2018, 144, 393-401. 
Environment: A Review of the Methods Used for Identification and Quantification. Environ. Sci. Technol. 2012, 46, 3060-3075.

(60) Abidli, S.; Antunes, J. C.; Ferreira, J. L.; Lahbib, Y.; Sobral, P.; El Menif, N. T. Microplastics in sediments from the littoral zone of the north Tunisian coast (Mediterranean Sea). Estuar. Coast. Shelf Sci. 2018, 205, 1-9.

(61) Alomar, C.; Estarellas, F.; Deudero, S. Microplastics in the Mediterranean Sea: Deposition in coastal shallow sediments, spatial variation and preferential grain size. Mar. Environ. Res. 2016, 115, 110.

(62) Ballent, A.; Corcoran, P.; Madden, O.; Helm, P.A.; Longstaffe, F.J. Sources and sinks of microplastics in Canadian Lake Ontarino nearshore, tributary and ach sediments. Mar. Pollut. Bull. 2016, 110, 383-395.

(63) Bergmann, M.; Wirzberger, W.; Krumpen, T.; Lorenz, C.; F. impke, S.; Tekman, M.B.; Gerdts, G. High quantities of microplastics in Arctic deep-sea sedimeı $s$ trom the HAUSGARTEN observatory. Environ. Sci. Technol. 2017, 51(19), 11000-11010.

(64) Blaskovic, A.; Fastelli, P.; Cizmek, H.; Guerranti., C.; Renzi, M. Plastic litter in sediments from the Croatian marine protected area of the natural pa k . ' ' 'elascica bay (Adriatic Sea). Mar. Pollut. Bull. 2017, 114, 583-586.

(65) Blumenroder, J.; Sechet, P.; Kakkonen, J.E.; Hartl, M.G.J. Microplastic contamination of intertidal sediments of Scapa Flow, Orkner. 4 ǐst assessment. Mar. Pollut. Bull. 2017, 124(1), 112-120.

(66) Carson, H.S.; Colbert, S.L.; K -101, M.J.; McDermid, K.J. Small plastic debris changes water movement and heat transfer through 1 ea!' sediments. Mar. Pollut. Bull. 2011, 62, 1708-1713.

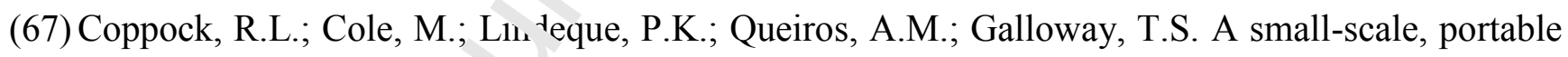
method for extracting microple stlu trom marine sediments. Environ. Pollut. 2017, 230, 829-837.

(68) Crichton, E.M.; Noe, Mı.; Gies, E.A.; Ross, P.S. A novel, density-independent and FTIRcompatible approach foor rapı extraction of microplastics from aquatic sediments. Anal. Methods. 2017, 9, 1419-1428.

(69) Dekiff, J.H.; Remy, D.; Klasmeier, J.; Fries, E. Occurrence and spatial distribution of microplastics in sediments from Norderney. Environ. Pollut. 2014, 186, 248-256.

(70) Falahudin, D.; Cordova, M. R.; Sun, X.; Yogaswara, D.; Wulandari, I.; Hindarti, D.; Arifin, Z. The first occurrence, spatial distribution and characteristics of microplastic particles in sediments from Banten Bay, Indonesia. Sci. Total Environ. 2020, 705, 135304.

(71) Fries, E.; Dekiff, J. H.; Willmeyer, J.; Nuelle, M. T.; Ebert, M.; Remy, D. Identification of polymer types and additives in marine microplastic particles using pyrolysis-GC/MS and scanning electron microscopy. Environ. Sci. Process. Impact. 2013, 15(10), 1949-1956. 


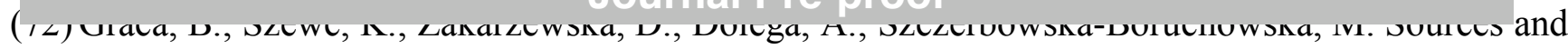

fate of microplastics in marine and beach sediments of the Southern Baltic Sea - a preliminary study. Environ. Sci. Pollut. Res. 2017, 24(8), 7650 - 7661.

(73) Graham, E.R.; Thompson, J.T. Deposit- and suspension-feeding sea cucumbers (Echinodermata) ingest plastic fragments. J. Exp. Mar. Biol. Ecol. 2009, 368, 22-29.

(74) Guerranti, C.; Cannas, S.; Scopetani, C.; Fastelli, P.; Cincinelli, A.; Renzi, M. Plastic litter in aquatic environments of Maremma Regional Park (Tyrrhenian Sea, Italy): Contribution by the Ombrone river and levels in marine sediments. Mar. Pollut. Bull. 2017, 117, 366-370.

(75) Haave, M.; Lorenz, C.; Primpke, S.; Gerdts, G. Different stories told by small and large microplastics in sediment-first report of microplastic concentrations in an urban recipient in Norway. Mar. Pollut. Bull. 2019, 141, 501-513.

(76) Imhof, H.K.; Ivleva, N.P.; Schmid, J.; Niessner, R.; L ،ro `cn, C. Contamination of beach

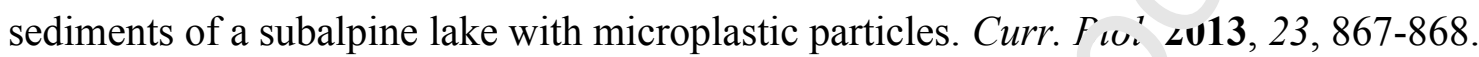

(77) Karlsson, T. M.; Vethaak, A. D.; Almroth, B. C.; ^ riesu, F.; van Velzen, M.; Hassellöv, M.; Leslie, H. A. Screening for microplastics in sediment, vate, marine invertebrates and fish: method development and microplastic accumulation. Mar. Pollut. Sull. 2017, 122(1-2), 403-408.

(78) Kazour, M.; Jemaa, S.; Issa, C.; Khalaf, G.; Aı ^r^, R. Microplastics pollution along the Lebanese coast (Eastern Mediterranean Basin): Occurrf ace in surface water, sediments and biota samples. Sci. Total Environ. 2019, 696, 133933.

(79) Leslie, H.A.; Brandsma, S.H.; Van Vei.en, M.J.M.; Vethaak, A.D. Microplastics en route: Field measurements in the Dutch river delta anc A.msterdam canals, wastewater treatment plants, North Sea sediments and biota. Environ. Int. 20*\%, 101, 133-142.

(80) Li, R.; Zhang, L.; Xue, B., Wang, Y. Abundance and characteristics of microplastics in the mangrove sediment of the ser.ii snulosed Maowei Sea of the south China sea: New implications for location, rhizosphere, and se乞 munt compositions. Environ. Pollut. 2019, 244, 685-692.

(81) Liebezeit, G.; Dubaisi, F. Microplastics in beaches of East Frisian Islands Spiekeroog and Kachelotplate. Bull Environ Contam Toxicol. 2012, 89, 213-217.

(82) Ling, S. D.; Sinclair, M.; Levi, C. J.; Reeves, S. E.; Edgar, G. J. Ubiquity of microplastics in coastal seafloor sediments. Mar. Pollut. Bull. 2017, 121(1-2), 104-110.

(83) Lorenz, C.; Roscher, L.; Meyer, M. S.; Hildebrandt, L.; Prume, J.; Löder, M. G.; Gerdts, G. Spatial distribution of microplastics in sediments and surface waters of the southern North Sea. Environ. Pollut. 2019, 252, 1719-1729.

(84) Lots, F. A.; Behrens, P.; Vijver, M. G.; Horton, A. A.; Bosker, T. A large-scale investigation of microplastic contamination: Abundance and characteristics of microplastics in European beach sediment. Mar. Pollut. Bull. 2017, 123(1-2), 219-226. 


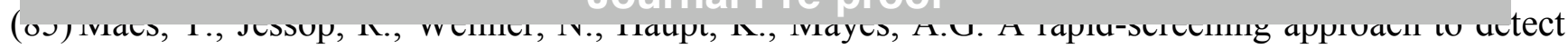
and quantify microplastics based on fluorescent tagging with Nile Red. Sci. Rep. 2017, 7, 44501.

(86) Martins, J.; Sobral, P. Plastic marine debris on the Portuguese coastline: A matter of size? Mar. Pollut. Bull. 2011, 62, 2649-2653.

(87) Mathalon, A.; Hill, P. Microplastic fibers in the intertidal ecosystem surrounding Halifax Harbor, Nova Scotia. Mar. Pollut. Bull. 2014, 81, 69-79.

(88) Mistri, M.; Infantini, V.; Scoponi, M.; Granata, T.; Moruzzi, L.; Massara, F.; Munari, C. Small plastic debris in sediments from the Central Adriatic Sea: Types, occurrence and distribution. Mar. pollut. Bull. 2017, 124(1), 435-440.

(89) Mu, J.; Qu, L.; Jin, F.; Zhang, S.; Fang, C.; Ma, X.; Wang, J. Abundance and distribution of microplastics in the surface sediments from the northern Bering and 'yukchi Seas. Environ. Pollut. 2019, $245,122-130$.

(90) Munari, C.; Infantini, V.; Scoponi, M.; Rastelli, E.; Co ill 'aesi, C.; Mistri, M. Microplastics in the sediments of Terra Nova Bay (Ross Sea, Antarctica). Mar. 'olıut. bull. 2017, 122(1-2), 161-165.

(91) Naji, A.; Esmaili, Z.; Khan, F. R. Plastic debris ar $1 \mathrm{~m}$ roplastics along the beaches of the Strait of Hormuz, Persian Gulf. Mar. pollut. bull. 2017a, 114(2), $105,-1062$.

(92) Naji, A.; Esmaili, Z.; Mason, S. A.; Vethaak t. I. The occurrence of microplastic contamination in littoral sediments of the Persian Gulf, Iran. F ıvl on. Sci. Pollut. Res. 2017b, 24(25), 20459-20468.

(93) Naji, A.; Nuri, M.; Amiri, P.; Niyogi, S. Imall microplastic particles (S-MPPs) in sediments of mangrove ecosystem on the northern coast $\sim \mathrm{f}_{\mathrm{t}_{\star}}$ - Persian Gulf. Mar. pollut. bull. 2019, 146, 305-311.

(94) Nel, H.A.; Froneman, P.W. A nua 't'iative analysis of microplastic pollution along the southeastern coastline of South Africa. Ma . ^? 'llut. Bull. 2015, 101, 274-279.

(95) Nor, N.H.M.; Obbard, J.P. Mıroplastics in Singapore's coastal mangrove ecosystems. Mar. Pollut. Bull. 2014, 79, 278-283

(96) Nuelle, M.T.; Deki1, J.iı; Remy, D.; Fries, E. A new analytical approach for monitoring microplastics in marine sedinıılts. Environ. Pollut. 2014, 184, 161-169.

(97) Peng, G.; Zhu, B.; Yang, D.; Su, L.; Shi, H.; Li, D. Microplastics in sediments of the Changjiang Estuary, China. Environ. Pollut. 2017, 225, 283-290.

(98) Phuong, N. N.; Poirier, L.; Lagarde, F.; Kamari, A.; Zalouk-Vergnoux, A. Microplastic abundance and characteristics in French Atlantic coastal sediments using a new extraction method. Environ. Pollut. $2018 \mathrm{c}, 243,228-237$.

(99) Reddy, M.S.; Basha, S.; Adimurthy, S.; Ramachandraiah, G. Description of the small plastics fragments in marine sediments along the Alang-Sosiya ship-breaking yard, India. Estu. Coast. Shelf Sci. 2006, 68, 656-660. 
Rodríguez-Espinosa, P. F. Microplastics in tourist beaches of Huatulco Bay, Pacific coast of southern Mexico. Mar. pollut. Bull. 2016, 113(1-2), 530-535.

(101) Saeed, T.; Al-Jandal, N.; Al-Mutairi, A.; Taqi, H. Microplastics in Kuwait marine environment: Results of first survey. Mar. pollut. Bull, 2020, 152, 110880.

(102) Sanchez-Vidal, A.; Thompson, R. C.; Canals, M.; de Haan, W. P. The imprint of microfibres in southern European deep seas. PloS one, 2018, 13(11).

(103) Stolte, A.; Forster, S.; Gerdts, G.; Schubert, H. Microplastic concentrations in beach sediments along the German Baltic coast. Mar. Pollut. Bull. 2015, 99, 216-229.

(104) Tang, G.; Liu, M.; Zhou, Q.; He, H.; Chen, K.; Zhang, H.; Chen, B. Microplastics and polycyclic aromatic hydrocarbons (PAHs) in Xiamen coastal arc aร: Implications for anthropogenic impacts. Sci. Total. Environ. 2018, 634, 811-820.

(105) Thompson, R.C.; Olsen, Y.; Mitchell, R.P.; Dav`s, A., Rowland, S.J.; John, A.W.G.; Mc Gonigle, D.; Russell, A.E. Lost at sea: where is all the plastic? Sclerice. 2004, 304, 838.

Tsang, Y.Y.; Mak, C.W.; Liebich, C.; Lam S. V.; Sze, E.T.P.; Chan, K.M. Microplastic pollution in the marine waters and sediments of Hong Kor.g. Mar. Pollut. Bull. 2017, 115, 20-28.

(107) Van Cauwenberghe, L.; Vanreusel, A., M .es, J.; Janssen, C.R. Microplastic pollution in deep-sea sediments. Environ. Pollut. 2013, 182 4५ ¡-4>9.

(108) Van Cauwenberghe, L.; Claessens. M.; \ฑ Degehuchte. M.B.; Janssen, C.R. Microplastics are taken up by mussels (Mytilus edulis) and I. owworms (Arenicola marina) living in natural habitats. Environ. Pollut. 2015b, 199, 10-17.

(109) Vermeiren, P.; Muñoz, C.; Ik j1ı`ר, K. Microplastic identification and quantification from organic rich sediments: A validated laborato:' piotocol. Environ. Pollut. 2020, 114298.

(110) Vianello, A.; Boldrin, ז $\cdot$ uerriero, P.; Moschino, V.; Rella, R.; Sturaro, A.; Da Ros, L. Microplastic particles in sea. neııs of Lagoon of Venice, Italy: First observations on occurrence, spatial patterns and identification. Esı. Coast. Shelf Sci. 2013, 130, 54-61.

(111) Wang, J.; Wang, M.; Ru, S.; Liu, X. High levels of microplastic pollution in the sediments and benthic organisms of the South Yellow Sea, China. Sci. Total. Environ. 2019, 651, 1661-1669.

(112) Wang, Q.; Shan, E.; Zhang, B.; Teng, J.; Wu, D.; Yang, X.; Zhao, J. Microplastic pollution in intertidal sediments along the coastline of China. Environ. Pollut. 2020, 114428.

(113) Wessel, C. C.; Lockridge, G. R.; Battiste, D.; Cebrian, J. Abundance and characteristics of microplastics in beach sediments: insights into microplastic accumulation in northern Gulf of Mexico estuaries. Mar. Pollut. Bull. 2016, 109(1), 178-183.

(114) Woodall, L.C.; Sanchez-Vidal, A.; Canals, M.; Paterson, G.L.J.; Coppock, R.; Sleight, V.; Calafat, A.; Rogers, A.D.; Narayanaswamy, B.E.; Thompson, R.C. The deep sea is a major sink for microplastic debris. R. Soc. Open Sci. 2014, 1, 140317. 


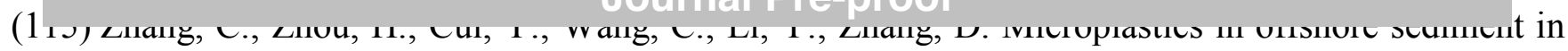

the yellow Sea and east China Sea, China. Environ. pollut. 2019a, 244, 827-833.

(116) Zhang, B.; Wu, D.; Yang, X.; Teng, J.; Liu, Y.; Zhang, C.; Wang, Q. Microplastic pollution in the surface sediments collected from Sishili Bay, North Yellow Sea, China. Mar. pollut. bull. 2019b, 141, 915.

(117) Zhao, J.; Ran, W.; Teng, J.; Liu, Y.; Liu, H.; Yin, X.; Wang, Q. Microplastic pollution in sediments from the Bohai Sea and the Yellow Sea, China. Sci. Total. Environ. 2018, 640, 637-645.

(118) Zheng, Y.; Li, J.; Cao, W.; Liu, X.; Jiang, F.; Ding, J.; Sun, C. Distribution characteristics of microplastics in the seawater and sediment: A case study in Jiaozhou Bay, China. Sci. Total. Environ. 2019, 674, 27-35.

(119) Zhu, L.; Bai, H.; Chen, B.; Sun, X.; Qu, K.; Xia, B. Microp ^rtic pollution in North Yellow Sea, China: Observations on occurrence, distribution and identification. 'cl. Total. Environ. 2018, 636, 20-29.

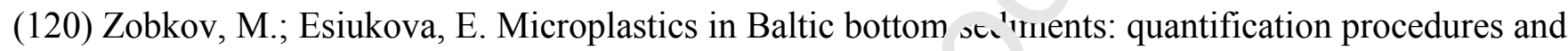
first results. Mar. pollut. bull. 2017, 114(2), 724-732.

(121) Frias, J.; Pagter, E.; Nash, R.; O'Connor, I.; Carret ${ }^{\star}$ ro, ).; Filgueiras, A.; Sobral, P. Standardised protocol for monitoring microplastics in sediments. 2018. Jeliv rable 4.2.

(122) Kershaw, P.; Turra, A.; Galgani, F. Guidelinrs ${ }^{c}$ or he Monitoring and Assessment of Plastic Litter in the Ocean. 2019. GESAMP reports and studi is.

(123) Paluselli, A., Fauvelle, V., Galgani, F., \& I`mpéré, R. Phthalates release and biodegradation from plastic fragments in seawater. Env. Sci. Techno', 2019, 53(1), 166-175.

(124) Panagiotopoulos, C., Sempéré, R . ( Ir ernosterer, I., Striby, L., Goutx, M., Van Wambeke, F., ... Lafont, R. Bacterial degradation of lirg varticles in the southern Indian Ocean using in vitro incubation experiments. Organic Geochemistry, ?.J2, 33(8), 985-1000.

(125) Löder, M. G.; Imhof, F.. ' ., Ladehoff, M.; Löschel, L. A.; Lorenz, C.; Mintenig, S.; Gerdts, G. Enzymatic purification of mi rupiastics in environmental samples. Environ. Sci. Technol. 2017, 51(24), 14283-14292.

(126) Cole, M.; Webb, H.; Lindeque, P.K.; Fileman, E.S.; Halsband, C.; Galloway, T.S. Isolation of microplastics in biota-rich seawater samples and marine organisms. Sci.Rep. 2014, 4, 4528.

(127) Li, J.; Qu, X.; Su, L.; Zhang, W. ; Yang, D. ; Kolandhasamy, P.; Li, D.; Shi, H. Microplastics in mussels along the coastal waters of China. Environ. Pollut. 2016, 214, 177-184.

(128) Gewert, B.; Ogonowski, M.; Barth, A. MacLeod, M. Abundance and composition of near surface microplastics and plastic debris in the Stockholm Archipelago, Baltic Sea. Mar. Pollut. Bull, 2017, 120(12), 292-302.

(129) Masura, J.; Baker, J. E.; Foster, G. D.; Arthur, C.; Herring, C. Laboratory methods for the analysis of microplastics in the marine environment: recommendations for quantifying synthetic particles in waters and sediments. 2015. 
from sand. A cost effective methodology based on sodium iodide recycling. Mar. pollut. Bull. 2017, 115(1-2), 120-129.

(131) Erni-Cassola, G.; Gibson, M. I.; Thompson, R. C.; Christie-Oleza, J. A. Lost, but found with Nile red: a novel method for detecting and quantifying small microplastics ( $1 \mathrm{~mm}$ to $20 \mu \mathrm{m})$ in environmental samples. Environ. sci. technol. 2017, 51(23), 13641-13648.

(132) Shim, W. J.; Song, Y. K.; Hong, S. H.; Jang, M. Identification and quantification of microplastics using Nile Red staining. Mar. Pollut. Bull. 2016, 113(1-2), 469-476.

(133) Loder, M.G.J.; Kuczera, M.; Mintenig, S.; Lorenz, C.; Gerdts, G. Focal plane array detector-based micro-fourier-transform infrared imaging for the analysis of microplastics in environmental samples. Environ.Chem. 2015, 12, 563-581.

(134) Dehaut, A.; Hermabessiere, L.; Duflos, G. Current frontiers anc recommendations for the study of microplastics in seafood. TrAC-Trend. Ana. Chem. 2019, 116, 34 v-? כy.

(135) Primpke, S.; Christiansen, S. H.; Cowger, W.; De Fro` 1, F., Deshpande, A.; Fischer, M.; Pittroff, M. EXPRESS: Critical Assessment of Analytical Meth sds for the Harmonized and Cost Efficient Analysis of Microplastics. Appl. Spectrosc. 2020, 0003702820\21465.

(136) Shim, W. J.; Hong, S. H.; Eo, S. E. Identificr t1 1 r rethods in microplastic analysis: a review. Ana. Method. 2017, 9(9), 1384-1391.

(137) Kappler, A.; Fisher, D.; Oberbeckmann, · Schernewski, G.; Labrenz, M.; Eichhorn, K.J.; Voit, B. Analysis of environmental microplastics $\mathrm{v}_{\text {j }}$ vibrational microspectroscopy: FTIR, Raman or both? Ana Bioanal Chem. 2016, 408(29), 8377-83 $) 1$.

(138) Araujo, C. F.; Nolasco, M. M ; ’ ibeiro, A. M.; Ribeiro-Claro, P. J. Identification of microplastics using Raman spectroscopy: latest tevelopments and future prospects. Water. Res. 2018, 142, 426440.Fettweis, M.; Du Four, I.; ¿c shnaekers, E.; Baeteman, C.; Francken, F.; Houziaux, J. S.; et al. Mud origin, characterisation and $\mathrm{h}_{\mathrm{n}} \mathrm{m}_{\mathrm{an}}$ activities (MOCHA). 2007.

(139) Chubarenko, I., Bagauv, A., Zobkov, M., \& Esiukova, E. On some physical and dynamical properties of microplastic particles in marine environment. Mar. pollut. Bull. 2016, 108(1-2), 105-112.

(140) Galgani, F.; Hanke, G.; Werner, S.; Oosterbaan, L.; Nilsson, P.; Fleet, D.; Kinsey, S.; Thompson, R. C.; VanFraneker, J.; Vlachogianni, T.; Scoullos, M.; Veiga, J.M.; Palatinus, A.; Matiddi, M.; Maes, T.; Korpinen, S.; Budziak, A.; Leslie, H.; Gago, H.; Liebezeit, G. Guidance on monitoring of marine litter in European seas. EUR - Scientific and Technical Research series-ISSN 1831-9424 (online), Luxembourg Publications Office of the European Union, eds. Hanke G.; Werner S.; Galgani F.; Veiga J.M; Ferreira M. 2013, (ISBN: 978-92-79-32709-4).

(141) Fauvelle, V.; Castro-Jimenez, J. ; Schmidt, N. ; Carlez, B.; Panagiotopoulos, C.; Sempere, R. Onesingle extraction procedure for the simultaneous determination of a wide range of polar and nonpolar organic contaminants in seawater. Front. Mar. Sci. 2018, 5, 295. 


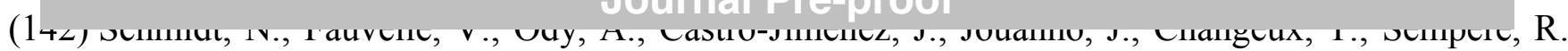

The amazon river: a major source of organic plastic additives to the tropical north atlantic?. Environ. Sci. Technol. 2019, 53(13), 7513-7521.

(143) Schmidt, N.; Castro-Jiménez, J.; Fauvelle, V.; Ourgaud, M.; Sempere, R. Occurrence of organic plastic additives in surface waters of the Rhône River (France). Environ. Pollut. 2020, 257, 113637.

(144) J. Gigault, A.T. Halle, M. Baudrimont, P.-Y. Pascal, F. Gauffre, T.-L. Phi, H. E1 Hadri, B. Grass1, S. Reynaud, Current opinion: what is a nanoplastic? Environ. Pollut. 2018, 235, 1030e1034. https://doi.org/10.1016/j.envpol.2018.01.024.

(145) Hernandez, L. M.; Yousefi, N.; Tufenkji, N. Are there nanoplastics in your personal care products? Environ. Sci. Technol. Lett. 2017, 4(7), 280-285.

(146) Ter Halle, A.; Jeanneau, L.; Martignac, M.; Jardé, E.; I ‘drono, B.; Brach, L.; Gigault, J. Nanoplastic in the North Atlantic subtropical gyre. Environ. sci. tec' 'nc' '2017, 51(23), 13689-13697.

(147) Materić, D.; Kasper-Giebl, A.; Kau, D.; Anten, M.; Gr лil 'ger, M.; Ludewig, E.; Holzinger, R. Micro-and Nanoplastics in Alpine Snow: A New Methor for Chemical Identification and (Semi) Quantification in the Nanogram Range. Environ. sci. techn'l. 2、20, 54(4), 2353-2359.

(148) Li, P.; Li, Q.; Hao, Z.; Yu, S.; Liu, J. Analvt.cal luethods and environmental processes of nanoplastics. J. Environ. Sci. 2020, 94, 88-99.

(149) Schwaferts, C.; Niessner, R.; Elsner, M, Iv 'eva, N. P. Methods for the analysis of submicrometerand nanoplastic particles in the environment. Trac Trend Anal. Chem. 2019, 112, 52-65.

(150) Sobhani, Z., Zhang, X., Gibson, $C$. ' 'Tidu, R., Mallavarapu, M., Fang, C. Identification and visualisation of microplastics/nanoplastics or Raman imaging (i): Down to $100 \mathrm{~nm}$. Water Res, 2020, 115658.

(151) Jakubowicz, I., Enebro, J., Vaiahmadi, N. Challenges in the search for nanoplastics in the environment-A critical reviev is nn the polymer science perspective. Polym Test, 2020, 106953.

(152) Ter Halle, A. Emerg 'g use thermo-analytical method coupled with mass spectrometry for the quantification of micro (nano, plastics in environmental samples. 2020, TrAC-Trend Ana Chem, 115979.

(153) Gillibert, R.; Balakrishnan, G.; Deshoules, Q.; Tardivel, M.; et al. Raman Tweezers for Small Microplastics and Nanoplastics Identification in Seawater. Environ. Sci. Technol. 2019. 53(15): 90039013. 
Decrar ation ur compermy micrest

The authors declare that they have no known competing financial interests or personal relationships that could have appeared to influence the work reported in this paper. 
Higningrits

- MPs in marine sediments have been published in at least 70 articles, at a total of 813 locations on all continents

- Areas studied are mainly in coastal environments, and the number of locations examined per study ranges from 1 to 72 .

- We recommend the use of a $\mathrm{NaCl}$ solution for the separation step.

- A digestion step using an $\mathrm{H}_{2} \mathrm{O}_{2}$ solution and automatic identification are recommended 